\title{
Response of ocean phytoplankton community structure to climate change over the 21st century: partitioning the effects of nutrients, temperature and light
}

\author{
I. Marinov ${ }^{1}$, S. C. Doney ${ }^{2}$, and I. D. Lima ${ }^{2}$ \\ ${ }^{1}$ Department of Earth and Environmental Science, University of Pennsylvania, \\ 240 S. 33rd Street, Hayden Hall 153, Philadelphia, PA 19104, USA \\ ${ }^{2}$ Department of Marine Chemistry and Geochemistry, Woods Hole Oceanographic Institution, \\ 266 Woods Hole Road, Woods Hole, MA 02543, USA
}

Received: 21 May 2010 - Published in Biogeosciences Discuss.: 16 June 2010

Revised: 1 November 2010 - Accepted: 18 November 2010 - Published: 2 December 2010

\begin{abstract}
The response of ocean phytoplankton community structure to climate change depends, among other factors, upon species competition for nutrients and light, as well as the increase in surface ocean temperature. We propose an analytical framework linking changes in nutrients, temperature and light with changes in phytoplankton growth rates, and we assess our theoretical considerations against model projections (1980-2100) from a global Earth System model. Our proposed "critical nutrient hypothesis" stipulates the existence of a critical nutrient threshold below (above) which a nutrient change will affect small phytoplankton biomass more (less) than diatom biomass, i.e. the phytoplankton with lower half-saturation coefficient $K$ are influenced more strongly in low nutrient environments. This nutrient threshold broadly corresponds to $45^{\circ} \mathrm{S}$ and $45^{\circ} \mathrm{N}$, poleward of which high vertical mixing and inefficient biology maintain higher surface nutrient concentrations and equatorward of which reduced vertical mixing and more efficient biology maintain lower surface nutrients. In the $45^{\circ} \mathrm{S}-$ $45^{\circ} \mathrm{N}$ low nutrient region, decreases in limiting nutrients associated with increased stratification under climate change - are predicted analytically to decrease more strongly the specific growth of small phytoplankton than the growth of diatoms. In high latitudes, the impact of nutrient decrease on phytoplankton biomass is more significant for diatoms than small phytoplankton, and contributes to diatom declines in the northern marginal sea ice and subpolar biomes. In the context of our model, climate driven increases in sur-
\end{abstract}

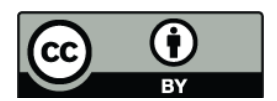

Correspondence to: I. Marinov (imarinov@sas.upenn.edu) face temperature and changes in light are predicted to have a stronger impact on small phytoplankton than on diatom biomass in all ocean domains. Our analytical predictions explain reasonably well the shifts in community structure under a modeled climate-warming scenario. Climate driven changes in nutrients, temperature and light have regionally varying and sometimes counterbalancing impacts on phytoplankton biomass and structure, with nutrients and temperature dominant in the $45^{\circ} \mathrm{S}-45^{\circ} \mathrm{N}$ band and light-temperature effects dominant in the marginal sea-ice and subpolar regions. As predicted, decreases in nutrients inside the $45^{\circ} \mathrm{S}$ $45^{\circ} \mathrm{N}$ "critical nutrient" band result in diatom biomass decreasing more than small phytoplankton biomass. Further stratification from global warming could result in geographical shifts in the "critical nutrient" threshold and additional changes in ecology.

\section{Introduction}

Earth system models are emerging with increasing sophistication in, for example, ocean ecology and biogeochemistry, with complex modules incorporating increasing number of plankton groups (e.g., Moore et al., 2002, 2004; Aumont et al., 2003; Lima et al., 2004; Le Quere et al., 2005; Schmittner et al., 2005; Follows et al., 2007) and improvements in the representation of limiting nutrients such as iron (e.g. Moore et al., 2006; Moore and Braucher, 2008). It is therefore important to analyze the basic ecological equations behind these models and offer analytical frameworks for understanding the behavior of such models, including the response to climate change. 
Understanding phytoplankton distribution is important, as phytoplankton are responsible for almost half of the total global primary production (Field et al., 1998). Phytoplankton consume inorganic carbon during photosynthesis and are an essential part of the transport of organic carbon from the upper to deep ocean. Diatoms, a phytoplankton group with siliceous tests, are thought to (a) be better at exporting carbon to the deep ocean and (b) be grazed less efficiently than nano or picophytoplankton. By contrast, small (nano or pico) phytoplankton are lighter and sink less readily than diatoms, so they tend to be associated with higher surface recycling of inorganic nutrients and carbon and less efficient carbon transport to the deep. Any future changes in the relative contribution of these or other important phytoplankton types to the total ocean biomass could thus have a significant impact on elemental stoichiometry, ocean biogeochemistry, and ocean carbon storage (e.g., Smetacek, 1999; Falkowski et al., 2004; Cermeno et al., 2008), as well as higher trophic levels that are dependent on them (Falkowski et al., 1998, etc.). Such ecological processes are poorly understood, and have only recently been incorporated in global climate models.

Predicting the response of phytoplankton community structure to climate change is complicated by the fact that phytoplankton growth depends on temperature and competition for light and nutrients, all of which change as the climate warms. While the overall effects of climate change on the biomass of phytoplankton has been addressed in recent studies (Boyd and Doney, 2002; Le Quere et al., 2003; Bopp et al., 2001, 2005), none of these studies has analyzed in a theoretical framework the separate impacts of changes in light, nutrients and temperature on the biomass and global distribution of main phytoplankton groups.

At low and mid-latitudes, the effect of reduced upwelling has been argued to result in reduced nutrient supply (and increased light efficiency), with a net negative impact on biomass and marine production (Sarmiento et al., 2004; Steinacher et al., 2010). Using data from an AMT cruise in the Atlantic Ocean, Cermeno et al. (2008) showed larger coccolithophorid-to-diatom biomass and diversity ratios for deeper nutricline depth (i.e., in more stable, less nutrient rich upper-ocean water columns) in the present ocean, and suggested a future transition from diatoms to coccolithophorids following a climate driven stabilization of the water column. These predictions are consistent with a couple of global modeling studies, which have projected a decrease in diatom relative abundance (fraction of diatoms to total biomass) in low and mid-latitudes (Bopp et al., 2005) with climate change, ascribed to decreasing nitrate in the surface layer. In contrast, a longer growing season and decreased ice cover has been suggested to lead to increased marine biomass and thus production at high latitudes (Bopp et al., 2001; Sarmiento et al., 2004; Doney, 2006; Steinacher et al., 2010).

Here we study the differential impact of climate driven changes in upper ocean nutrients, temperature and light on phytoplankton biomass and community structure. The present analysis focuses on the surface, annual mean dynamics. The behavior of the ecological system is based on a set of complex, coupled differential equations describing three main phytoplankton types: diatoms, small phytoplankton and diazotrophs, as well as model nutrients. Laboratory and field incubation studies demonstrate that different phytoplankton species drawdown nutrients with greater or lesser efficiency. This can be expressed using nutrient half saturation $(K)$ values, with lower $K$ phytoplankton drawing down nutrients more efficiently in the stratified low latitudes. Furthermore, different phytoplankton types have different light requirements, and their response to light will also depend on their chlorophyll to carbon ratio $(\mathrm{Chl} / \mathrm{C})$, the initial slope $\alpha$ of the photosynthesis-irradiance (P-I) curve, nutrient concentrations and temperature.

In the present paper we propose a new "critical nutrient hypothesis": changes in nutrients, whether positive of negative, will always change the biomass of small phytoplankton (a) more than diatom biomass in the nutrient-scarce low and mid latitudes, but (b) less than diatom biomass in nutrient rich high latitudes, with the separation between these two types of biomes determined by a "critical nutrient" value. Furthermore, we show analytically and verify in a fully coupled global climate model simulation for the 1980-2100 period that climate driven increases in temperature and changes in light always preferentially affect small phytoplankton, the phytoplankton with lower half saturation coefficient $K$, compared to diatoms.

The above mechanisms are developed and verified in the framework of a Geider et al. (1998) photosynthesis model incorporated in the CCSM3 global climate model. While Geider et al. (1998) has become the model of choice for representing light limitation and phytoplankton growth in the most recent state-of-the-art climate models (Le Quere et al., 2005; Moore et al., 2002, 2004), future research needs to be done to confirm the validity of our proposed mechanisms in a wide spectrum of models and in nature.

\section{Biogeochemistry Ecosystem Model}

Our analysis is based on global numerical simulations using the Community Climate System Model version 3 (CCSM3, see Collins et al., 2006a), to which has been added prognostic land and ocean carbon cycle and ecosystem dynamics. We use the low spatial resolution version of the CCSM3 as detailed by Yeager et al. (2006). The CCSM3 atmosphere and land models share the identical grid $\mathrm{T} 31 \times 3$, a 96 by 48 spectral dynamical grid of approximately $3.75^{\circ}$ horizontal resolution, and the atmosphere component model (Collins et al., 2006b) has 26 levels in the vertical at this resolution. The land component has been modified from the Community Land Model version 3 (Collins et al., 2006a) to incorporate coupled carbon and nitrogen cycles as well as an improved hydrological scheme, as described in Thornton et al. (2009). 
The ocean physics component of CCSM3 is the Parallel Ocean Program (POP), a z-level, hydrostatic, primitive equation model (Smith and Gent, 2002; Collins et al., 2006a). The version integrated here has the so-called gx3v5 resolution, i.e., $3.6^{\circ}$ in longitude, $0.8^{\circ}$ to $1.8^{\circ}$ in latitude (finer resolution near the equator), and 25 vertical levels with enhanced vertical resolution in the upper compared to the deep ocean (Yeager et al., 2006). The ocean model uses the Gent and McWilliams (1990) parameterization of mesoscale eddy transport effects and (in the vertical) the Large et al. (1994) K-profile parameterization of surface boundary-layer dynamics and interior diapycnal mixing.

The biogeochemistry-ecosystem-circulation ocean model (BEC) model consists of upper ocean ecological (Moore et al., 2002, 2004) and full-depth biogeochemical (Doney et al., 2006) modules embedded in the global 3-D POP ocean general circulation model. The biogeochemistry module follows Doney et al. (2006) and is an expanded version of the Ocean Carbon Model Intercomparison Project (OCMIP) biotic model (Najjar et al., 2007). This model includes a carbonate chemistry module, which dynamically calculates surface $p \mathrm{CO}_{2}$ from simulated temperature, salinity, dissolved inorganic carbon and total alkalinity, as well as air-sea gas exchange for $\mathrm{CO}_{2}$ and $\mathrm{O}_{2}$. A dynamical iron cycle is incorporated with seasonally-varying atmospheric dust deposition, water-column scavenging and continental sediment source using the parameterizations in Moore et al. (2008). The absorption of shortwave radiation depends on the simulated chlorophyll distribution, thus allowing for biological feedbacks in ocean physics.

The following phytoplankton groups are represented: small phytoplankton class (which incorporates nano/picoplankton and coccolithophores), nitrogen-fixing diazotrophs, and diatoms. A single zooplankton class grazes differentially on the phytoplankton groups. Additional prognostic variables include suspended and sinking particulate matter, DIC (dissolved inorganic carbon), Alk (alkalinity), $\mathrm{O}_{2}$ (oxygen) and dissolved nutrients: $\mathrm{NH}_{4}$ (ammonia), $\mathrm{NO}_{3}$ (nitrate), $\mathrm{PO}_{4}$ (phosphate), $\mathrm{SiO}_{3}$ (silicate) and $\mathrm{Fe}$ (iron). The model fixes the phytoplankton $\mathrm{C} / \mathrm{N} / \mathrm{P}$ ratios but allows for variations in $\mathrm{Fe} / \mathrm{C}, \mathrm{Si} / \mathrm{C}$ and $\mathrm{Chl} / \mathrm{C}$ ratios depending on ambient nutrient and light availability. The parameterization of nitrogen fixation follows Moore et al. (2006). A thorough validation of ocean-only simulations was recently performed by comparing with a host of observables (Doney et al., 2009).

The sequential spinup of the coupled climate model is detailed in Thornton et al. (2009), resulting in a global model with a stable climate and carbon cycle. In brief, a 1000year preindustrial control simulation is followed by a transient simulation for the 1870-2099 period. We use 18701999 historical data to prescribe fossil fuel $\mathrm{CO}_{2}$ emissions, and $\mathrm{CO}_{2}$ emissions from the SRES A2 scenario for the period 2000-2099. The balance between fossil fuel emissions and net land and ocean $\mathrm{CO}_{2}$ sources/sinks governs model at- mospheric $\mathrm{CO}_{2}$. The time-evolving simulated atmospheric $\mathrm{CO}_{2}$ concentration is used in the atmospheric radiative transfer routines, and the land and ocean carbon sources/sinks respond to changes in simulated atmospheric $\mathrm{CO}_{2}$, temperature and climate.

In our model, the diatom, small phytoplankton, and diazotroph chlorophyll and biomass (carbon) tracers each are determined by an equation of the form:

$$
\begin{aligned}
\frac{\partial P_{x}}{\partial t} & +\nabla \cdot\left(\boldsymbol{u} P_{x}\right)-\nabla \cdot\left(K \cdot \nabla P_{x}\right) \\
& =\mu_{x} \cdot P-G\left(P_{x}\right)-m_{x} \cdot P_{x}-A\left(P_{x}\right)
\end{aligned}
$$

where the left-hand side terms include advection and diffusion, and the biological terms on the right-hand side represent a source term due to growth and multiple sinks due to grazing (Holling type III), linear mortality and aggregation (square dependence on $P_{x}$ ).

The photosynthetic specific growth rate $\mu_{x}$ for each phytoplankton type $x$ (diatoms, small phytoplankton and diazotrophs) is parameterized along the lines of Geider et al. (1998) as the product of a maximum phytoplankton Cspecific growth rate $\mu_{\text {ref }}$ (referenced to $30^{\circ} \mathrm{C}$ ), a temperature function $\left(T_{\mathrm{f}}\right)$, a nutrient functional response $\left(V_{x}\right)$ and a light availability function $\left(L_{x}\right)$ :

$\mu_{x}=\mu_{\mathrm{ref}} \cdot T_{\mathrm{f}} \cdot V_{x} \cdot L_{x}$

where $\mu_{\text {ref }}$ is $3 \mathrm{~d}^{-1}$ for diatoms and small phytoplankton (Geider et al., 1998) and $0.4 \mathrm{~d}^{-1}$ for diazotrophs. The temperature function is the so-called Q10 function:

$T_{\mathrm{f}}=2^{\left(\frac{T-30^{\circ} \mathrm{C}}{10^{\circ} \mathrm{C}}\right)}$

While the temperature function is identical for all phytoplankton classes, different phytoplankton have different nutrient and light requirements (i.e., different $V_{x}$ and $L_{x}$ ). For each of the three phytoplankton types, the most limiting nutrient governs the nutrient functional response as follows:

$$
\begin{aligned}
& V_{\text {diat }}=\min \left(V_{\text {diat }}^{\mathrm{Fe}}, V_{\text {diat }}^{N}, V_{\text {diat }}^{\mathrm{SiO}_{3}}, V_{\text {diat }}^{\mathrm{PO}_{4}}\right) ; \\
& V_{\mathrm{sp}}=\min \left(V_{\mathrm{sp}}^{\mathrm{Fe}}, V_{\mathrm{sp}}^{N}, V_{\mathrm{sp}}^{\mathrm{PO}_{4}}\right) ; \\
& V_{\mathrm{diaz}}=\min \left(V_{\mathrm{diaz}}^{\mathrm{Fe}}, V_{\mathrm{diaz}}^{\mathrm{PO}_{4}}\right)
\end{aligned}
$$

where $V_{x}^{\mathrm{NO}_{3}}=\frac{\frac{\mathrm{NO}_{3}}{K_{x}^{\mathrm{NO}_{3}}}}{1+\frac{\mathrm{NO}_{3}}{K_{x}^{\mathrm{NO}_{3}}}+\frac{\mathrm{NH}_{4}}{K_{x}^{\mathrm{NH}_{4}}}} ; V_{x}^{\mathrm{NH}_{4}}=\frac{\frac{\mathrm{NH}_{4}}{K_{x}^{\mathrm{NH}_{4}}}}{1+\frac{\mathrm{NO}_{3}}{K_{x}^{\mathrm{NO}_{3}}}+\frac{\mathrm{NH}_{4}}{K_{x}^{\mathrm{NH}_{4}}}} ;$

$V_{x}^{N}=V_{x}^{\mathrm{NO}_{3}}+V_{x}^{\mathrm{NH}_{4}}$

$V_{x}^{\mathrm{PO}_{4}}=\frac{\mathrm{PO}_{4}}{\mathrm{PO}_{4}+K_{x}^{\mathrm{PO}_{4}}} ; V_{x}^{\mathrm{Fe}}=\frac{\mathrm{Fe}}{\mathrm{Fe}+K_{x}^{\mathrm{Fe}}} ; V_{x}^{\mathrm{SiO}_{3}}=\frac{\mathrm{SiO}_{3}}{\mathrm{SiO}_{3}+K_{x}^{\mathrm{SiO}_{3}}}$

The light function $L_{x}$ follows a modified form of the Geider et al. (1998) dynamic growth model and includes photoadaptation parameterized with adaptive $\mathrm{Chl} / \mathrm{C}$ ratios:

$$
L_{x}\left(I_{\mathrm{par}}, T_{\mathrm{f}}, V_{x}\right)=1-\exp \left(\frac{-\alpha_{x} \cdot \theta_{x}^{c} \cdot I_{\mathrm{par}}}{\mu_{\mathrm{ref}} V_{x} T_{\mathrm{f}}}\right)
$$


Table 1. Model parameters.

\begin{tabular}{|c|c|c|c|}
\hline Parameter & Value & Units & Definition \\
\hline$\alpha_{\mathrm{sp}}, \alpha_{\text {diat }}$ & 0.3 & $\mathrm{mmol} \mathrm{C} \mathrm{m}^{2}(\mathrm{mgChl} \mathrm{W} \mathrm{d})^{-1}$ & Initial slope of P-I curve for small phyto and diatoms \\
\hline$\alpha_{\mathrm{diaz}}$ & 0.036 & $\mathrm{mmol} \mathrm{C} \mathrm{m}^{2}(\mathrm{mgChl} \mathrm{W} \mathrm{d})^{-1}$ & Initial slope of P-I curve for diazotrophs \\
\hline$\mu_{\mathrm{ref}}^{\mathrm{sp}}, \mu_{\mathrm{ref}}^{\mathrm{diat}}$ & 3 & $d^{-1}$ & Max. small phytoplankton and diatom $\mathrm{C}$ specific growth rate at $T_{\text {ref }}$ \\
\hline$\mu_{\mathrm{ref}}^{\operatorname{diaz}}$ & 0.4 & $d^{-1}$ & Max. diazotrophs $\mathrm{C}$ specific growth rate at $T_{\text {ref }}$ \\
\hline$K_{\mathrm{sp}}^{\mathrm{NO}_{3}}$ & 0.5 & $\operatorname{mmol~} \mathrm{Nm}^{-3}$ & Small phyto. $\mathrm{NO}_{3}$ half saturation coefficient \\
\hline$K_{\mathrm{sp}}^{\mathrm{NH}_{4}}$ & 0.005 & $\operatorname{mmol~N~m}{ }^{-3}$ & Small phyto. $\mathrm{NH}_{4}$ half saturation coefficient \\
\hline$K_{\mathrm{sp}}^{\mathrm{Fe}}$ & $6 \times 10^{-5}$ & $\mathrm{mmol} \mathrm{Fe} \mathrm{m}^{-3}$ & Small phyto. Fe half saturation coefficient \\
\hline$K_{\mathrm{sp}}^{\mathrm{PO}_{4}}$ & $3.125 \times 10^{-4}$ & $\mathrm{mmol} \mathrm{Fe} \mathrm{m}{ }^{-3}$ & Small phyto. Fe half saturation coefficient \\
\hline$K_{\text {diat }}^{\mathrm{NO}_{3}}$ & 2.5 & $\mathrm{mmol} \mathrm{N} \mathrm{m}^{-3}$ & Diatom $\mathrm{NO}_{3}$ half saturation coefficient \\
\hline$K_{\text {diat }}^{\mathrm{NH}_{4}}$ & 0.08 & $\mathrm{mmol} \mathrm{N} \mathrm{m}^{-3}$ & Diatom $\mathrm{NH}_{4}$ half saturation coefficient \\
\hline$K_{\text {diat }}^{\mathrm{Fe}}$ & $1.5 \times 10^{-4}$ & $\mathrm{mmol} \mathrm{Fe} \mathrm{m}{ }^{-3}$ & Diatom Fe half saturation coefficient \\
\hline$K_{\text {diat }}^{\mathrm{PO}_{4}}$ & 0.005 & $\mathrm{mmol} \mathrm{PO}_{4} \mathrm{~m}^{-3}$ & Diatom $\mathrm{PO}_{4}$ half saturation coefficient \\
\hline$K_{\text {diat }}^{\mathrm{SiO}_{3}}$ & 1 & $\mathrm{mmol} \mathrm{SiO}_{3} \mathrm{~m}^{-3}$ & Diatom Si half saturation coefficient \\
\hline$K_{\mathrm{diaz}}^{\mathrm{Fe}}$ & $1 \times 10^{-4}$ & $\mathrm{mmol} \mathrm{Fe} \mathrm{m}^{-3}$ & Diazotrophs Fe half saturation coefficient \\
\hline$K_{\mathrm{diaz}}^{\mathrm{PO}_{4}}$ & 0.005 & $\mathrm{mmol} \mathrm{PO}_{4} \mathrm{~m}^{-3}$ & Diazotrophs $\mathrm{PO}_{4}$ half saturation Coefficient \\
\hline$u_{\mathrm{sp}}^{\max }$ & 2.75 & $\mathrm{~d}^{-1}$ & Max zoo growth rate on small phytopl at $30^{\circ} \mathrm{C}$ \\
\hline$u_{\text {diat }}^{\max }$ & 2.07 & $\mathrm{~d}^{-1}$ & Max zoo growth rate on diatoms at $30^{\circ} \mathrm{C}$ \\
\hline$u_{\mathrm{diaz}}^{\max }$ & 1.2 & $d^{-1}$ & Max zoo growth rate on diazotrophs at $30^{\circ} \mathrm{C}$ \\
\hline$m_{z}$ & 0.1 & $d^{-1}$ & zooplankton linear mortality rate \\
\hline$a_{\mathrm{sp}}^{\max }$ & 0.2 & $\mathrm{~d}^{-1}$ & max. aggregation rate for small phyto \\
\hline$a_{\text {diat }}^{\max }$ & 0.2 & $\mathrm{~d}^{-1}$ & max. aggregation rate for diatoms \\
\hline$a_{\text {diat }}^{\min }$ & 0.01 & $d^{-1}$ & min. aggregation rate for diatoms \\
\hline$g_{\mathrm{sp}}, g_{\mathrm{diaz}}$ & 1.05 & $\mathrm{mmol} \mathrm{C} \mathrm{m}^{-3}$ & zooplankton grazing coefficient for small phytoplankton and diazotrophs \\
\hline$g_{\text {diat }}$ & $0.9 \cdot 1.05$ & $\mathrm{mmol} \mathrm{C} \mathrm{m}^{-3}$ & zooplankton grazing coefficient, diatoms \\
\hline$p_{\mathrm{sp}}, p_{\text {diat }}$ & 0.009 & $(\mathrm{mmol} \mathrm{C})^{-1} \mathrm{~m}^{3} \mathrm{~d}^{-1}$ & Small phytoplankton/diatom quadratic mortality rate \\
\hline
\end{tabular}

where $\alpha_{x}$ is the initial slope of the photosynthesis-irradiance (P-I) curve for phytoplankton type $x$ assumed to be 0.3 for diatoms and small phytoplankton (Geider et al., 1998), 0.036 for diazotrophs and we defined

$\theta_{x}^{c}=\left(\frac{\mathrm{Chl}}{\mathrm{C}}\right)_{x}$

The ratio inside the exponential in Eq. (6) is a ratio between the instantaneous light harvesting capacity $\alpha_{x} \theta_{x}^{c} I_{\text {par }}$ and the maximum photosynthetic rate $\mu_{\text {ref }} T_{\mathrm{f}} V_{x}$. At high light intensity, $L_{x}$ approaches 1 and the photosynthetic growth rate
(Eq. 2) approaches its high limit $\mu_{\mathrm{ref}} T_{\mathrm{f}} V_{x}$. In low light, $L_{x}$ approaches $\alpha_{x} \theta_{x}^{c} I_{\mathrm{par}} /\left(\mu_{\mathrm{ref}} T_{\mathrm{f}} V_{x}\right)$ and the photosynthetic rate approaches the linear relationship $\alpha_{x} \theta_{x}^{c} I_{\text {par }}$, which is independent of temperature and nutrient limitation.

The largest loss term in Eq. (1) is due to grazing. The model has one zooplankton class with biomass $Z$ that grazes adaptively on phytoplankton and large detritus; grazing follows a Holling type III functional response:

$G\left(P_{x}\right)=u_{x}^{\max } \cdot T_{\mathrm{f}} \cdot\left(\frac{P_{x}^{2}}{P_{x}^{2}+g_{x}^{2}}\right) Z$ 


\section{a. Surface Diatom Biomass}

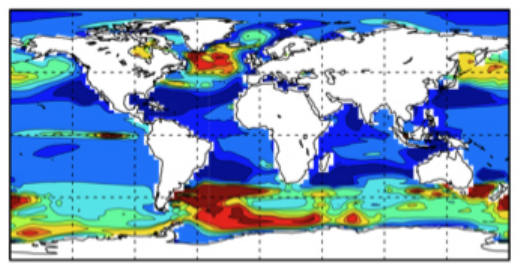

c. Small Phytoplankton Biomass

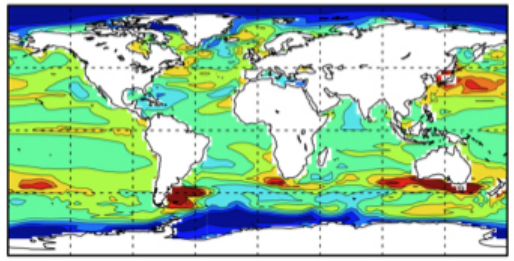

e. Diazotroph Biomass

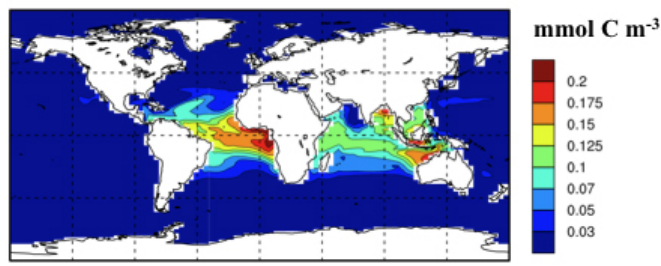

\section{b. Diatom Nutrient Limitation}

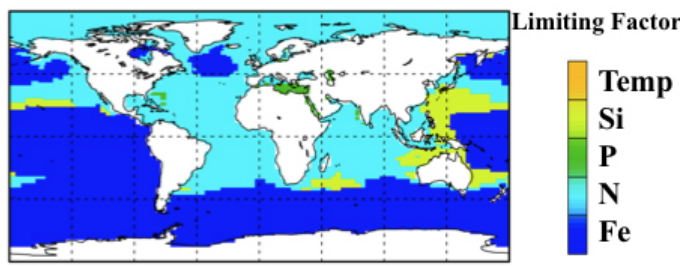

d. Small Phytoplankton nutrient Limitation

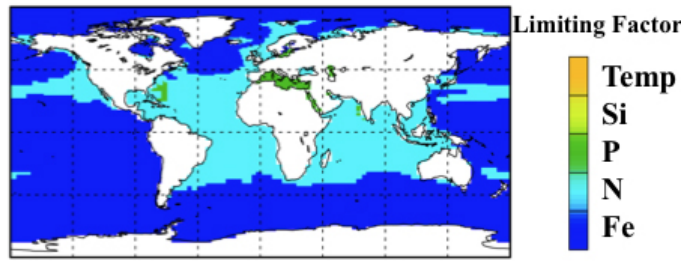

f. Diazotroph Limitation

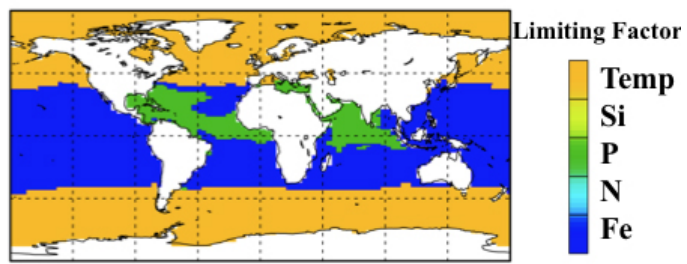

Fig. 1. Global maps of (a, c, e) surface diatom, small phytoplankton and dizotroph biomass in mmol C/m $\mathrm{m}^{3}$ as well as $(\mathbf{b}, \mathbf{d}, \mathbf{f})$ the mixed layer depth limiting nutrients averaged over the control period, years 1980-1999.

Grazing is higher for small phytoplankton (larger maximum grazing rate $u^{\max }$, see Table 1) and is assumed for simplicity to have the same temperature dependence via $T_{\mathrm{f}}$ as phytoplankton growth. $g_{x}$ is a zooplankton grazing coefficient set to the same value for small phytoplankton and diazotrophs, and smaller for diatoms (Table 1). Finally, the loss of biomass via aggregation of organic matter is parameterized as:

$\operatorname{Aggreg}\left(P_{x}\right)=\min \left(a_{x}^{\max } P_{x}, p_{x} P_{x}^{2}\right)$

\section{Analysis and results}

\subsection{Ecological response to climate change}

The three phytoplankton types compete for nutrients and light; the relative magnitude of the half-saturation $K_{x}$ coefficients for the different species (Table 1) as well as the nutrient saturated growth rate are essential for determining the outcome of competition. Because of their high affinity for nutrients and low resource requirements (lower $K$ than diatoms, see Table 1), small phytoplankton dominate over diatoms and diazotrophs roughly from about $45^{\circ} \mathrm{S}$ to $45^{\circ} \mathrm{N}$ (Figs. 1 and 2). In the competition theory literature (e.g., Tilman, 1977), organisms such as small phytoplankton that invest energy in adaptation to low nutrient concentrations are called "K strategists". Diatom relative (or fractional) abundance is defined as the diatom biomass divided by the total phytoplankton biomass (Fig. 2). Diatoms, so-called " $r$ strategists" in the ecological literature, are better at taking up nutrients in low light, high nutrient environments and thus dominate in the highly seasonal high latitudes, where they exhibit higher nutrient saturated growth rates. Diatoms follow the vertical velocity patterns, with higher values in upwelling and convective regions such as the equatorial Pacific, Southern Ocean and upwelling regions on the west coast of continents (Figs. 1a, 2). Light and temperature limited diazotrophs grow only in low latitude warm waters where they are limited by either iron or phosphorus and fix all the nitrogen they need from $\mathrm{N}_{2}$ gas (Fig. 1e, f). Increased stratification results in a decrease in low latitude phosphate from 1980 to 2100 and a switch from iron to phosphorus limitation for Atlantic and Indian low latitude diazotrophs (figure not shown). Since diazotrophs have much smaller biomass concentrations than either the small phytoplankton or the diatoms, our analysis will mostly focus on the competition between the latter two species.

The nutrient limitation patterns for diatoms and small phytoplankton are similar (Fig. 1b, d), with nitrogen as the main limiting nutrient in the mid-latitude Atlantic and Indian Oceans for both diatoms and small phytoplankton, and iron the main limiting nutrient in the Pacific and in all ocean 


\section{Diatom relative abundance}

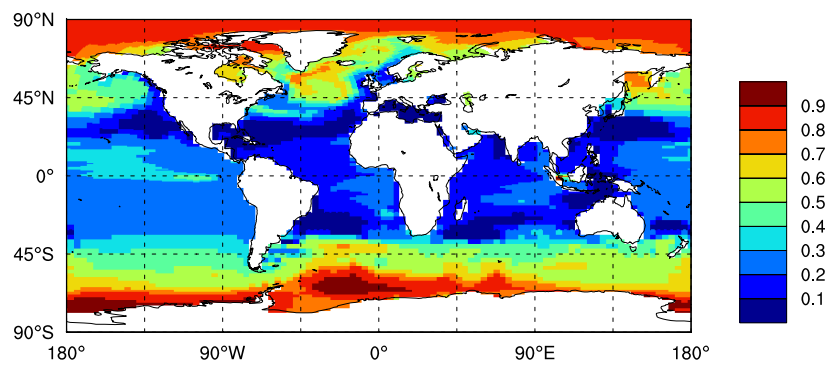

Fig. 2. Diatom relative abundance (no units) defined as the fractional contribution of diatom biomass to phytoplankton biomass, averaged for years 1980-1999.

basins south of $45^{\circ} \mathrm{S}$. Significant differences are found in the Arctic Ocean, where diatoms are nitrogen limited while small phytoplankton are iron limited, and in the western Pacific Ocean, where diatoms are limited by silicon rather than iron, an essential nutrient necessary for diatom shell formation. Overall, the large-scale diatom and small phytoplankton nutrient limitation patterns change little with climate change from 1980 to 2100 (figure not shown).

Model projections of climate driven changes in physics and nutrients are shown in Figs. 3-4. Climate change results in a warmer surface ocean and an increase in the strength of the global hydrological cycle, acting to freshen the surface ocean particularly at the poles (Fig. 3). The combination of warmer and fresher surface waters reduces surface water density and acts to increase the vertical stratification of the upper water column. Oceanic vertical stratification, expressed in Fig. $3 \mathrm{~b}$ as the density difference between surface and $200 \mathrm{~m}$, increases at most locations in the ocean with climate warming, and results in reduced supply of subsurface nutrients to the surface throughout most of the ocean, as apparent in surface nitrate (Fig. 4b).

A goal of this paper to understand the separate impacts of large-scale changes in nutrients, temperature and light on phytoplankton specific growth rates, and see to what extent these changes are reflected in the biomass and relative abundances of the different phytoplankton. Figure 5 shows climate driven changes in specific growth rate, biomass and carbon relative abundance (defined for diatoms as the ratio of diatom biomass to total phytoplankton biomass) for both small phytoplankton and diatoms. Changes are approximated from the linear trends of the deseasonalized monthly data for 1980-2099 (multiplied by 120 years). Climate driven changes in biomass are partly driven by changes in specific growth rates, as suggested by similarities in the respective large scale patterns in the $45^{\circ} \mathrm{S}-45^{\circ} \mathrm{N}$ domain and parts of the Southern Ocean. Areas where the patterns strongly diverge (e.g., north of $45^{\circ} \mathrm{N}$ for diatoms) are areas where grazing (and to a lesser extent linear loss and aggregation) have first order importance.
Decreasing nitrate supply over large areas in the Indian and Atlantic Ocean north of $45^{\circ} \mathrm{S}$ (Fig. 4b) translates in decreases in diatom growth rate, biomass and abundance (Figs. 3d, e, 5b, e, h). In the high latitudes of the Northern Hemisphere, diatoms show a stronger negative response to nutrient decline than small phytoplankton, such that their relative fractional abundance decreases significantly (by 6 to $15 \%$ ) north of about $40^{\circ} \mathrm{N}$ (Figs. 3e, $5 \mathrm{~h}$ and diatom-small phytoplankton abundance differences in Fig. 5i). Overall, we note a close correlation between diatom nutrient functional response and diatom biomass and abundance, as previously reported (e.g. Bopp et al., 2005). The shape of the zonal mean change in diatom relative abundance (Fig. 3e) is similar to that reported by Bopp et al. (2005).

A reduction in mixed layer depth (due to enhanced stratification) combines with shrinking ice cover (Fig. 3c) to increase light availability for phytoplankton in high latitudes, as discussed in previous work (e.g., Doney, 2006). Small phytoplankton show a stronger positive response than diatoms to increases in high latitude light availability, such that small phytoplankton growth rate, biomass and relative abundance increase both south of $60^{\circ} \mathrm{S}$ and north of $60^{\circ} \mathrm{N}$ (Fig. 5a, d, g).

Can we analytically separate the individual impacts of changing light, nutrients and temperature on phytoplankton growth rates? We use a standard Taylor series expansion of the specific growth rate (Eq. 2) around some initial state:

$$
\begin{aligned}
& \Delta \mu_{x}=\left.\frac{\partial \mu_{x}}{\partial I_{\mathrm{par}}}\right|_{V_{x}, T_{\mathrm{f}} \text { constant }} \cdot \Delta I_{\mathrm{par}}+\left.\frac{\partial \mu_{x}}{\partial V_{x}}\right|_{I_{\mathrm{par}}, T_{\mathrm{f}} \text { constant }} \\
& \cdot \Delta V_{x}+\left.\frac{\partial \mu_{x}}{\partial T_{\mathrm{f}}}\right|_{I_{\mathrm{par}}, V_{x} \text { constant }} \cdot \Delta T_{\mathrm{f}}
\end{aligned}
$$

As is customary, we retain the first order (linear) terms in the expansion, dropping higher order quadratic terms (e.g. $\left.\Delta T_{\mathrm{f}}^{2}, \Delta T_{\mathrm{f}}, \Delta I_{\mathrm{par}}\right)$ which tend to be considerably smaller than the first order perturbations. Taking into account the fact that the light limitation function $L_{x}$ is a function of $I_{\mathrm{par}}, V_{x}$ and $T_{\mathrm{f}}$, we expand the terms in Eq. (10) as detailed in Appendix A and get:

$\Delta \mu_{x}=\Delta \mu_{x}^{\text {light }}+\Delta \mu_{x}^{\text {nutr }}+\Delta \mu_{x}^{\text {temp }}$

The light function, nutrient and temperature contributions to the growth rate change are:

$$
\begin{aligned}
\Delta \mu_{x}^{\text {light }} & =\alpha_{x} \theta_{x}^{c} I_{\mathrm{par}} \cdot\left(\frac{\Delta I_{\mathrm{par}}}{I_{\mathrm{par}}}-\frac{\Delta V_{x}}{V_{x}}-\frac{\Delta T_{\mathrm{f}}}{T_{\mathrm{f}}}\right) \\
& \cdot \exp \left(\frac{-\alpha_{x} \cdot \theta_{x}^{c} \cdot I_{\mathrm{par}}}{\mu_{\mathrm{ref}} V_{x} T_{\mathrm{f}}}\right) \\
\Delta \mu_{x}^{\text {nutr }}= & \mu_{\mathrm{ref}} \cdot T_{\mathrm{f}} L_{x} \cdot \Delta V_{x} \\
\Delta \mu_{x}^{\text {temp }} & =\mu_{\mathrm{ref}} \cdot L_{x} V_{x} \cdot \Delta T_{\mathrm{f}}
\end{aligned}
$$

where $I_{\mathrm{par}}, V_{x}$ and $T_{\mathrm{f}}$ represent the initial state, and the $\Delta$ notation refers to small perturbations around this state. 


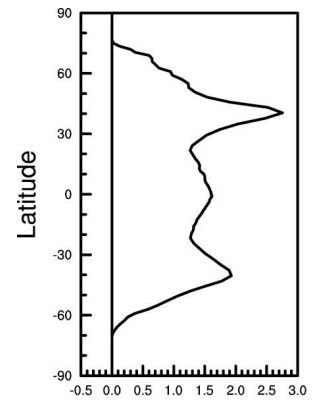

a. $\triangle \mathrm{SST}\left({ }^{\circ} \mathrm{C}\right)$

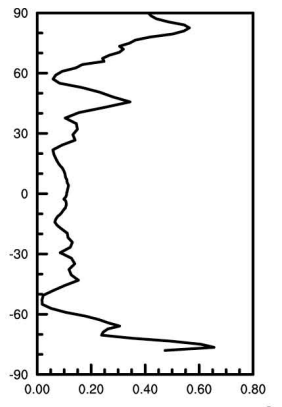

b. $\Delta$ Stratification $\left(\mathrm{kg} / \mathrm{m}^{3}\right)$

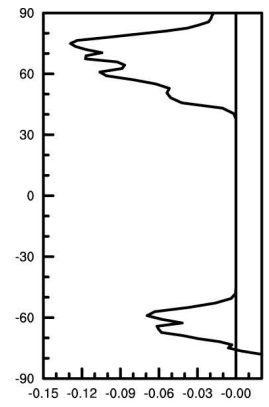

c. $\Delta$ lce fraction
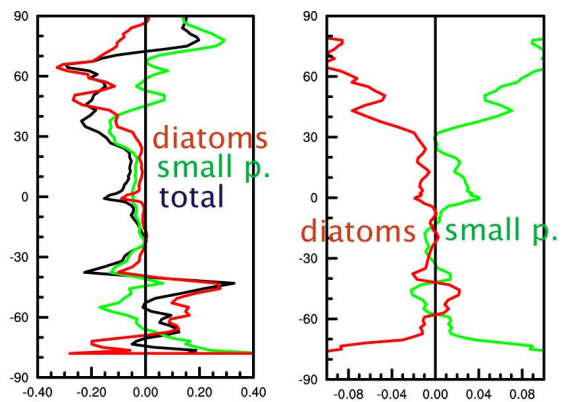

d. $\Delta$ Biomass $\left(\mathrm{mgC} / \mathrm{m}^{3}\right)$ e. $\Delta$ Relative Abundance $(\%)$

Fig. 3. Zonal mean response to climate change (calculated as difference from years 1980-1999 to 2080-2099) of the: (a) sea surface temperature in ${ }^{\circ} \mathrm{C}$, (b) fractional change in sea surface stratification, defined as surface minus $200 \mathrm{~m} \mathrm{density}\left(\mathrm{kg} / \mathrm{m}^{3}\right),(\mathbf{c})$ the ocean area covered by sea ice in $10^{12} \mathrm{~m}^{2}$ per degree, (d) total (black), small phytoplankton (green) and diatom (red) biomass (mgC/ $\mathrm{m}^{3}$ ) and (e) diatom (red) and small phytoplankton (green) relative abundance (no units).

a. Surface $\mathrm{NO}_{3}$

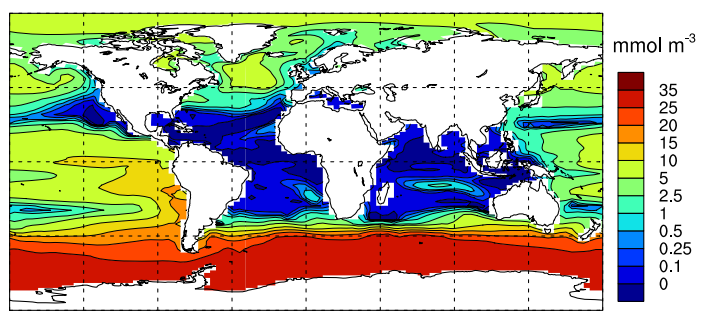

c. Surface $\mathrm{Fe}$

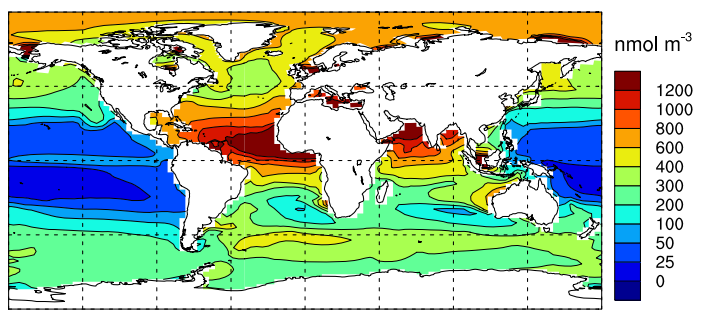

e. Surface $I_{p a r}$

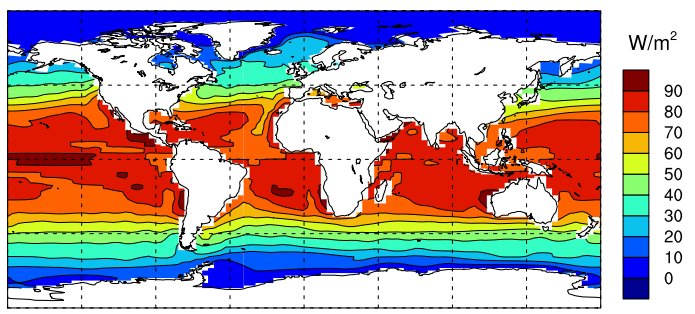

b. $\Delta$ Surface $\mathrm{NO}_{3}$

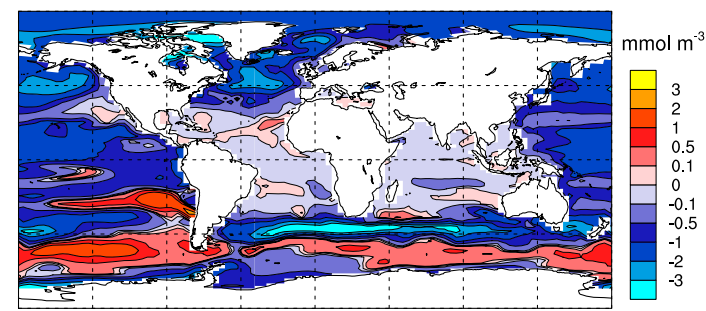

d. $\Delta$ Surface Fe

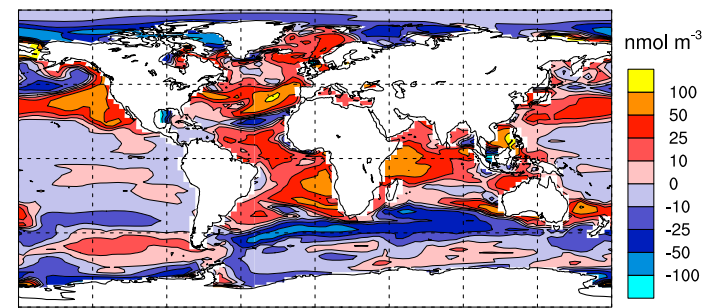

f. $\Delta$ Surface $\mathrm{I}_{\mathrm{par}}$

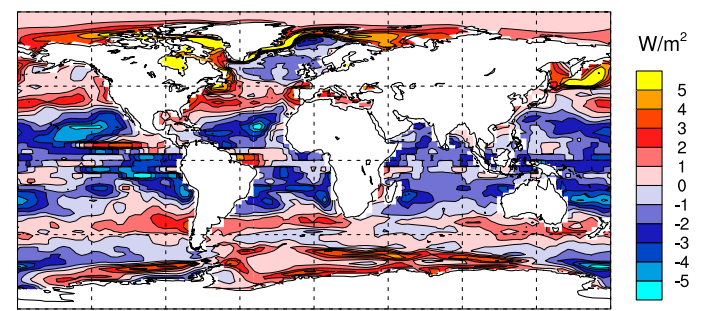

Fig. 4. (a-b): surface nitrate in $\mathrm{mmol} / \mathrm{m}^{3}$ averaged over 1980-1999 and the change in nitrate between years 1980-1999 and 2080-2099. Same as above for $(\mathbf{c}-\mathbf{d})$ the surface iron in $\mathrm{nmol} / \mathrm{m}^{3}$ and $(\mathbf{e}-\mathbf{f})$ surface irradiance $I_{\text {par }}$ in $\mathrm{W} / \mathrm{m}^{2}$. Surface irradiance takes into account the decreasing ice coverage.

The growth rate terms Eq. (12a)-(12c) show the contribution of changes in light, nutrients and temperature to biomass changes. These terms, calculated from the linear trends in monthly light, nutrients and temperature for years 19802099, are illustrated in Fig. 6 for both diatoms and small phytoplankton.
We next define the marginal sea ice biomes as the Northern or Southern Hemisphere provinces covered by sea ice during some part of the year (but which are not permanently covered by sea ice), averaged for years 1980-1999. The subpolar biomes are defined as the areas poleward of $45^{\circ} \mathrm{N}$ or $45^{\circ} \mathrm{S}$ not included in the marginal sea ice biome. The 
Small Phytoplankton

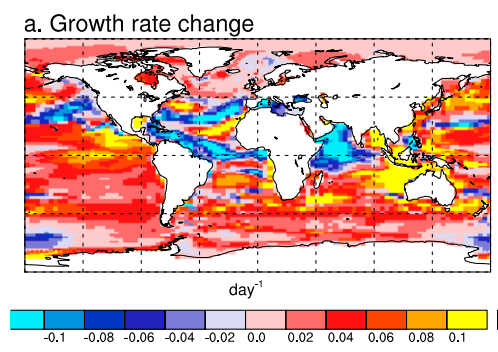

d. Biomass change

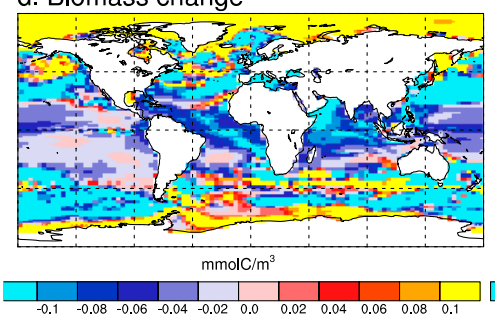

g. Rel. Abundance change

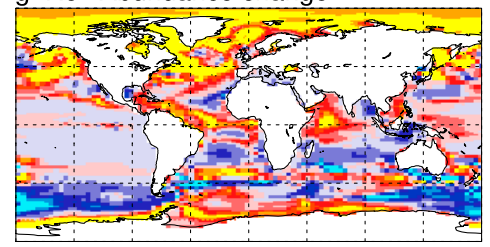

\begin{tabular}{l|l|l|l|l|l|l|l|l|l|l|l|}
\hline & & & & & & & & & & & \\
\hline-0.1 & -0.08 & -0.06 & -0.04 & -0.02 & 0.0 & 0.02 & 0.04 & 0.06 & 0.08 & 0.1
\end{tabular}
Diatoms

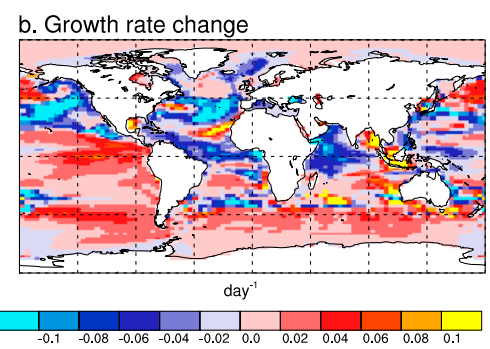

e. Biomass change

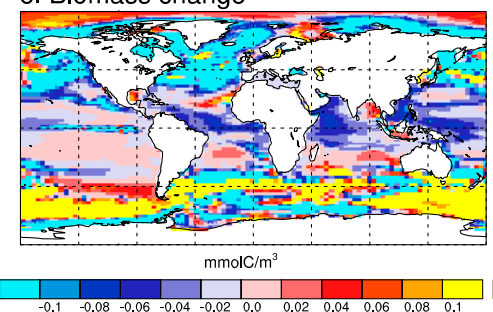

h. Rel. Abundance change

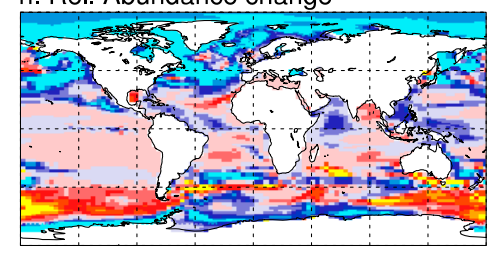

Diatoms - Small Phytoplankton
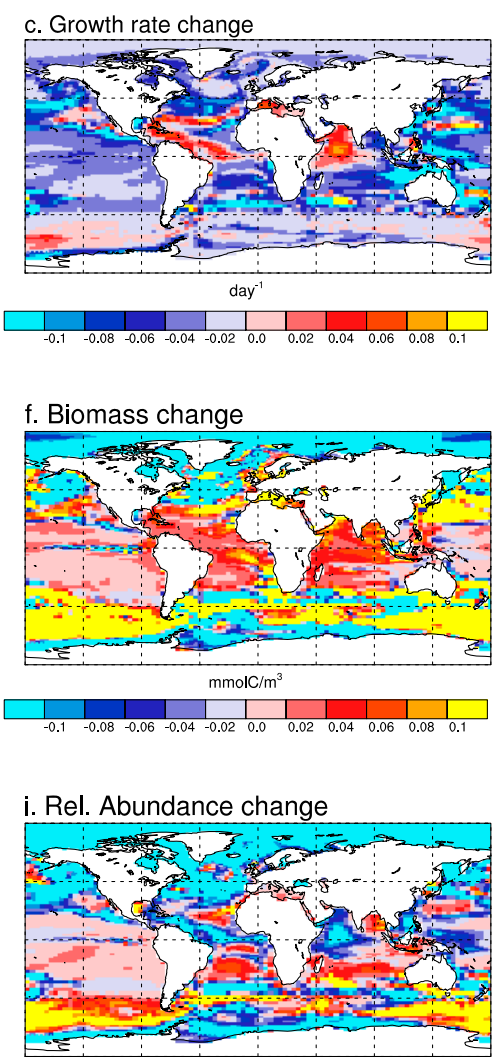

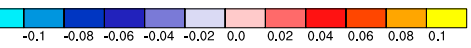

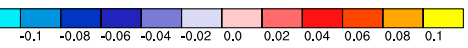

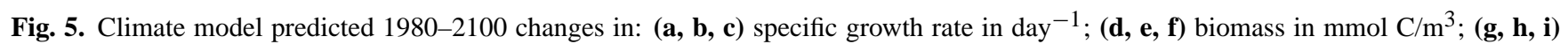
fractional abundance - no units - for small phytoplankton (left panels), diatoms (middle panels), and the difference between diatoms and small phytoplankton (right hand panels). Specific growth rate change $\Delta \mu_{x}$ calculated from the 1980-2100 linear trend multiplied by 120 years.

impact of changes temperature, nutrients, light and grazing (from 1980 to 2100) on phytoplankton growth rate and total biomass, as well as the fractional changes in zooplankton abundances, nitrate, iron and surface irradiance are illustrated over five different domains of the ocean in Fig. 7 (the $45^{\circ} \mathrm{S}-45^{\circ} \mathrm{N}$ biome) and Fig. 8 (the marginal sea-ice and the subpolar biomes).

We make three immediate observations:

1. Climate driven decreases in nutrients have a larger impact on small phytoplankton specific growth rate than on diatom specific growth rate in the $45^{\circ} \mathrm{S}-45^{\circ} \mathrm{N}$ biome. The opposite is the case in the four high latitude biomes.

2. Climate driven changes in light, whether positive or negative, have a stronger impact on small phytoplankton than on diatom specific growth rate in all biomes.

3. Increasing temperature increases small phytoplankton specific growth rate more than it increases diatoms specific growth rate in all biomes.
In Sects. 3.2-3.4 we provide a mathematical analysis that can help us understand each of these three effects and test our predictions against the modeled climate simulations. We conclude with a detailed discussion of modeled ecology in each of these biomes.

\subsection{The critical nutrient hypothesis}

Where two or more phytoplankton species co-exist, they can interact via competition for light and nutrients. Previous work with multifunctional group marine ecosystem models, such as the one used here, indicates that there are large portions of the global surface ocean where the growth of simulated small phytoplankton and diatoms are limited by the same nutrient allowing for species competition (Moore et al., 2004). We focus here our analysis on those regions where nitrogen and iron are limiting for both small phytoplankton and diatoms (Fig. 1b, d), acknowledging that the results are not applicable in regions where the phytoplankton groups are limited by different nutrients (e.g., silicon for diatoms). While not discussed here, phosphorus limitation 
Small Phytoplankton

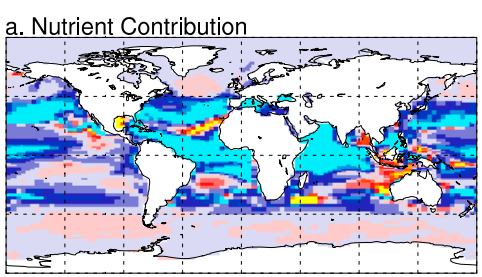

d. Temperature Contribution

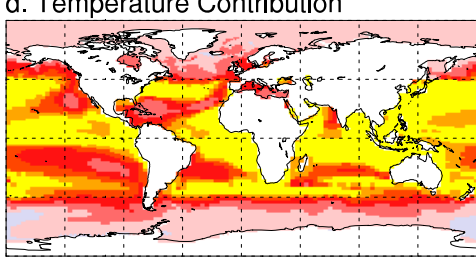

g. Light Contribution

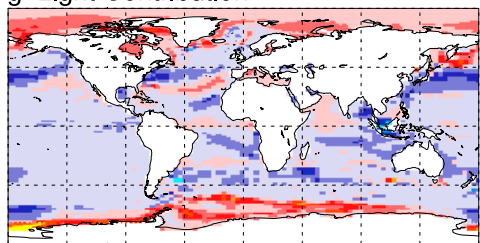

Diatoms

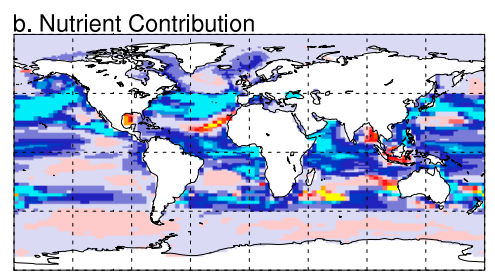

e. Temperature Contribution

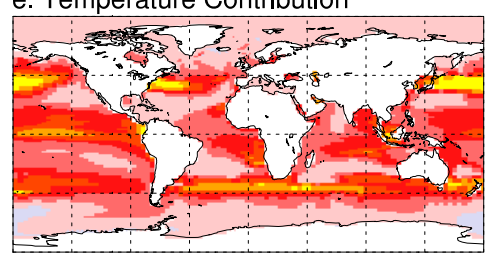

h. Light Contribution

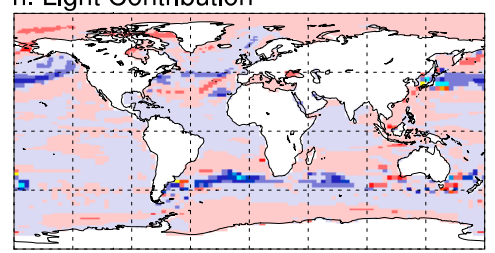

Diatoms - Small Phytoplankton

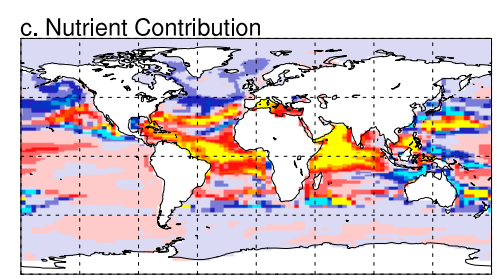

f. Temperature Contribution

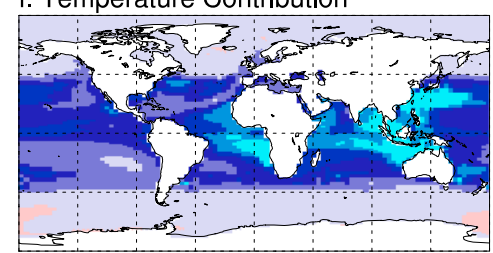

i. Light Contribution

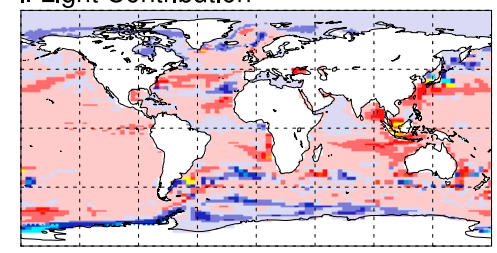

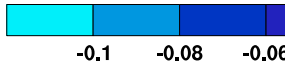

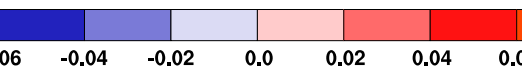

\begin{tabular}{ll|l|l|} 
& & & \\
0.06 & 0.08 & 0.1
\end{tabular}

Fig. 6. What drives the 1980 to 2100 change in phytoplankton specific growth rate? Shown are the (a, b, c) nutrient contribution $\Delta \mu_{x}^{\text {nutr }}$; $(\mathbf{d}, \mathbf{e}, \mathbf{f})$ temperature contribution $\Delta \mu_{x}^{\text {temp }} ;(\mathbf{g}, \mathbf{h}, \mathbf{i})$ light contribution to the growth rate trend $\Delta \mu_{x}^{\text {light }}$. All contributions calculated from the respective 1980-2100 modeled linear trends multiplied by 120 years, in units of day ${ }^{-1}$, and shown for small phytoplankton (left panels), diatoms (middle panels), and the difference between diatoms and small phytoplankton (right hand panels).

may be important on the smaller regional basis and the same basic analysis framework would apply. In order to consider the role of each individual term in Eq. (11) on the overall growth rates, we first analyze the contribution of nutrients to growth rate $\Delta \mu_{x}^{\text {nutr }}$ (Eq. 12b).

Figure 9a, c shows the nutrient functional response $V_{x}$ for diatoms and small phytoplankton as a function of the limiting nutrient, with higher half saturation coefficient $K_{x}$ values for diatoms resulting in lower values: $V_{\mathrm{sp}}>V_{\text {diat }}$. The shape of the nutrient functional response ensures that there is a critical nutrient value above which the slope of $V_{\text {diat }}$ is steeper than the slope of $V_{\mathrm{sp}}$ (Fig. 9b, d) such that for a given change in limiting nutrient $\Delta N$, the resulting change in nutrient functional response is larger for diatoms than for small phytoplankton: $\left|\Delta V_{\text {diat }}\right|>\left|\Delta V_{\mathrm{sp}}\right|$. Conversely, for nutrient concentrations below the critical nutrient level, an increase (decrease) in the limiting nutrient will result in a larger increase (decrease) in nutrient functional response for small phytoplankton than for diatoms: $\left|\Delta V_{\mathrm{sp}}\right|>\left|\Delta V_{\text {diat }}\right|$ and therefore $\left|\Delta \mu_{\mathrm{sp}}^{\text {nutr }}\right|>\left|\Delta \mu_{\text {diat }}^{\text {nutr }}\right|$. That is, below the critical nutrient level, a nutrient change $\Delta N$ has a larger effect on the growth rate of the plankton group with the low $K$ value (small phytoplankton are influenced more strongly in low nutrient environments).
Mathematically, we consider the phytoplankton nutrient functional response for a generic limiting nutrient $V_{x}=N /\left(N+K_{x}\right)$ and calculate:

$$
\frac{\partial V_{x}}{\partial N}=\frac{\partial}{\partial N}\left(\frac{N}{N+K_{x}^{N}}\right)=\frac{K_{x}^{N}}{\left(N+K_{x}^{N}\right)^{2}}
$$

The critical nutrient value is achieved when the nutrient functional response slopes are equal

$$
\begin{aligned}
& \frac{\partial V_{\mathrm{sp}}}{\partial N}=\frac{\partial V_{\text {diat }}}{\partial N} \text { implies } \frac{K_{\text {diat }}^{N}}{\left(N+K_{\text {diat }}^{N}\right)^{2}}=\frac{K_{\mathrm{sp}}^{N}}{\left(N+K_{\mathrm{sp}}^{N}\right)^{2}} \\
& \text { or } N_{\text {critical }}=\sqrt{K_{\text {diat }}^{N} K_{\mathrm{sp}}^{N}}
\end{aligned}
$$

Then, as illustrated graphically in Fig. 9b, d for a small change in nutrient $\Delta N$ :

$$
\begin{aligned}
N & \leq N_{\text {critical }} \text { implies } \frac{\partial V_{\mathrm{sp}}}{\partial N} \geq \frac{\partial V_{\text {diat }}}{\partial N}, \\
& \left|\Delta V_{\mathrm{sp}}\right| \geq\left|\Delta V_{\text {diat }}\right| \text { and }\left|\Delta \mu_{\mathrm{sp}}^{\text {nutr }}\right| \geq\left|\Delta \mu_{\text {diat }}^{\text {nutr }}\right|
\end{aligned}
$$

and conversely 


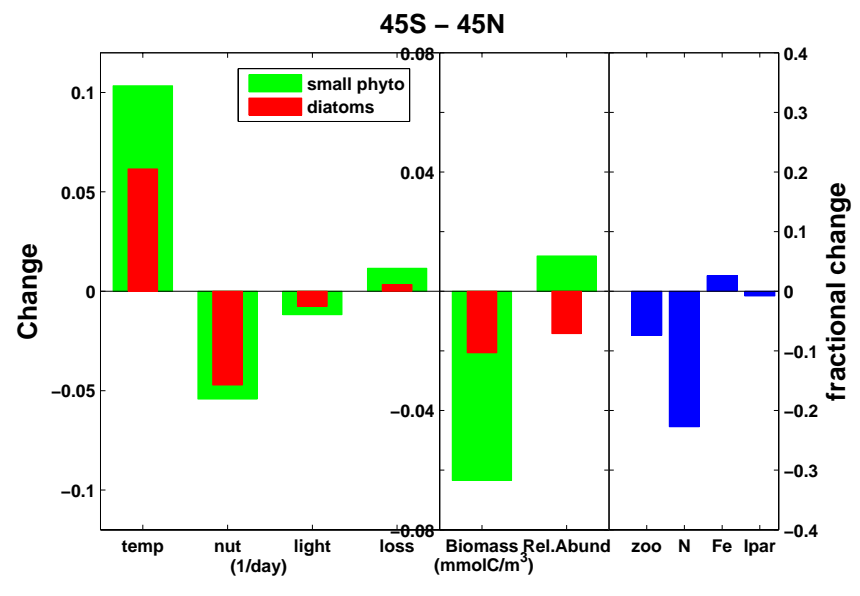

Fig. 7. Climate driven changes in small phytoplankton (green) and diatom (red) growth and loss terms averaged over the $45^{\circ} \mathrm{S}-45^{\circ} \mathrm{N}$ region. Shown are the temperature, nutrient and light contributions to the change in specific growth rate in units of day $^{-1}\left(\Delta \mu_{x}^{\text {temp }}\right.$, $\Delta \mu_{x}^{\text {nutr }}, \Delta \mu_{x}^{\text {light }}$ calculated from the respective linear trends multiplied by 120 years; diatom or small phytoplankton biomass used as weight in biome averaging); changes in total phytoplankton loss rate (sum of grazing, linear loss, aggregation rate, in day ${ }^{-1}$ ); the 1980-2100 linear trends in biomass $\left(\mathrm{mmol} \mathrm{C} / \mathrm{m}^{3}\right)$ and the 1980 2100 change in diatom relative abundance (no units, total biomass used as weight in biome averaging). The fractional changes from 1980-1999 to 2080-2099 in zooplankton carbon, nitrate, iron and total irradiance $I_{\text {par }}$ are shown in blue (no units).

$$
\begin{aligned}
& N>N_{\text {critical }} \text { implies } \frac{\partial V_{\mathrm{sp}}}{\partial N}<\frac{\partial V_{\text {diat }}}{\partial N}, \\
& \left|\Delta V_{\mathrm{sp}}\right|<\left|\Delta V_{\text {diat }}\right| \text { and }\left|\Delta \mu_{\mathrm{sp}}^{\text {nutr }}\right|<\left|\Delta \mu_{\text {diat }}^{\text {nutr }}\right|
\end{aligned}
$$

where we made use of Eq. (12b). Note that the critical nutrient concept makes sense only for $K_{\text {sp }}$ different from $K_{\text {diat }}$. In our model, the critical nutrient value for nitrate and iron limited regions are given by:

$$
\begin{aligned}
& \mathrm{NO}_{3 \text { critical }}=\sqrt{K_{\text {diat }}^{\mathrm{NO}_{3}} K_{\mathrm{sp}}^{\mathrm{NO}_{3}}}=1.18 \mathrm{mmol} \mathrm{NO}_{3} / \mathrm{m}^{3} \\
& \mathrm{Fe}_{\text {critical }}=\sqrt{K_{\text {diat }}^{\mathrm{Fe}} K_{\mathrm{sp}}^{\mathrm{Fe}}}=95 \mathrm{nmol} \mathrm{Fe} / \mathrm{m}^{3}
\end{aligned}
$$

where we disregard for the purpose of this paper the complications to the $\mathrm{NO}_{3}$ critical calculation brought in by the presence of $\mathrm{NH}_{4}$ (Eq. 5). Let us assume that we are in a region in which nutrients are below the critical nutrient threshold. If the nutrient term $\Delta \mu_{x}^{\text {nutr }}$ is large enough to dominate the total growth rate change such that $\Delta \mu_{x} \cong \Delta \mu_{x}^{\text {nutr }}$, a given change in the limiting nutrient will affect more small phytoplankton than diatoms, i.e., $\left|\Delta \mu_{\text {sp }}\right| \geq\left|\Delta \mu_{\text {diat }}\right|$.

In regions of $\mathrm{Fe}\left(\mathrm{NO}_{3}\right)$ limitation, we compare directly surface $\mathrm{Fe}\left(\mathrm{NO}_{3}\right)$ concentration with the $\mathrm{Fe}_{\text {critical }}$ $\left(\mathrm{NO}_{3}\right.$ critical $)$ values calculated above. We broadly distinguish two regimes, as shown in Fig. 10a. A first one in which efficient biology and reduced vertical mixing of nutrients ensure that limiting nutrients are below critical nutrient lev- els roughly corresponds to the $45^{\circ} \mathrm{S}-45^{\circ} \mathrm{N}$ band, and is the region where nutrient-driven changes in small phytoplankton growth is expected to dominate over changes in diatom growth (green regions in Fig. 10a). A second one in which nutrients are above the critical value (Eq. 16) roughly corresponds to the high latitudes poleward of $45^{\circ}$ (light blue regions in Fig. 10a), and is the region where nutrient-driven changes in diatom growth should dominate over changes in small phytoplankton growth. These two regimes correspond respectively to the left hand side and the right hand side of the critical nutrient value in Fig. 9b, d.

\section{Regime 1: $45^{\circ} \mathrm{S}$ to $45^{\circ} \mathrm{N}$}

In the Atlantic and Indian oceans north of $45^{\circ} \mathrm{S}$, nitrate is the limiting nutrient for both diatoms and small phytoplankton and efficient biology draws down nutrients below the critical level, i.e. $\mathrm{NO}_{3}<\mathrm{NO}_{3}$ critical. Over most of the Pacific north of $45^{\circ} \mathrm{S}, \mathrm{Fe}$ is low and the limiting nutrient, and $\mathrm{Fe}<\mathrm{Fe}_{\text {critical }}$. Our theory then implies that for a given temporal change in the limiting nutrient, the absolute change in nutrient functional response should be larger for small phytoplankton than for diatoms: $\left|\Delta V_{\mathrm{sp}}\right|>\left|\Delta V_{\text {diat }}\right|$ and therefore $\left|\Delta \mu_{\mathrm{sp}}^{\text {nutr }}\right|>\left|\Delta \mu_{\text {diat }}^{\text {nutr }}\right|$.

In order to check our theory, we calculate $\Delta \mu_{\mathrm{sp}}^{\text {nutr }}$ and $\Delta \mu_{\text {diat }}^{\text {nutr }}$ from the temporal linear trends for the time period 1980-2100 from model monthly data. The low and midlatitude Atlantic and Indian oceans are primarily characterized by increased stratification and decreased supply of nitrate to the ocean surface in a future climate, resulting in decreased phytoplankton nitrate functional response and decreased $\mu_{x}^{\text {nutr }}$. Analysis of model results confirms that in this region the climate induced decreases in $V_{\mathrm{sp}}$ and $\mu_{\mathrm{sp}}^{\text {nutr }}$ are larger than the corresponding decreases in $V_{\text {diat }}$ and $\mu_{\text {diat }}^{\text {nutr }}$ (Fig. 6a-c). Indeed, the regions of $\mu_{\mathrm{sp}}^{\text {nutr }}$ versus $\mu_{\text {diat }}^{\text {nutr }}$ dominance shown in Fig. 10b are almost identical with those predicted by the critical nutrient hypothesis (Fig. 10a). The critical nutrient hypothesis predicts correctly that climate change has a larger impact on small phytoplankton growth rates compared to diatom growth rate in the low and midlatitude oceans, as reflected by Fig. 7 and the diatom - small phytoplankton growth rate differences in Fig. 5.

\section{Regime 2: south of $45^{\circ} \mathrm{S}$ and north of $45^{\circ} \mathrm{N}$}

Phytoplankton are iron limited in the Southern Ocean south of $45^{\circ} \mathrm{S}$, while both iron and nitrate limited in the Arctic and North Atlantic north of $45^{\circ} \mathrm{N}$. Let us consider regions in which small phytoplankton and diatoms are limited by the same nutrient. Inefficient biology and a seasonal supply of nutrients from below ensure that the concentrations of limiting nutrients in these regions are higher than critical nutrient values. For a given change in the limiting nutrient, the 

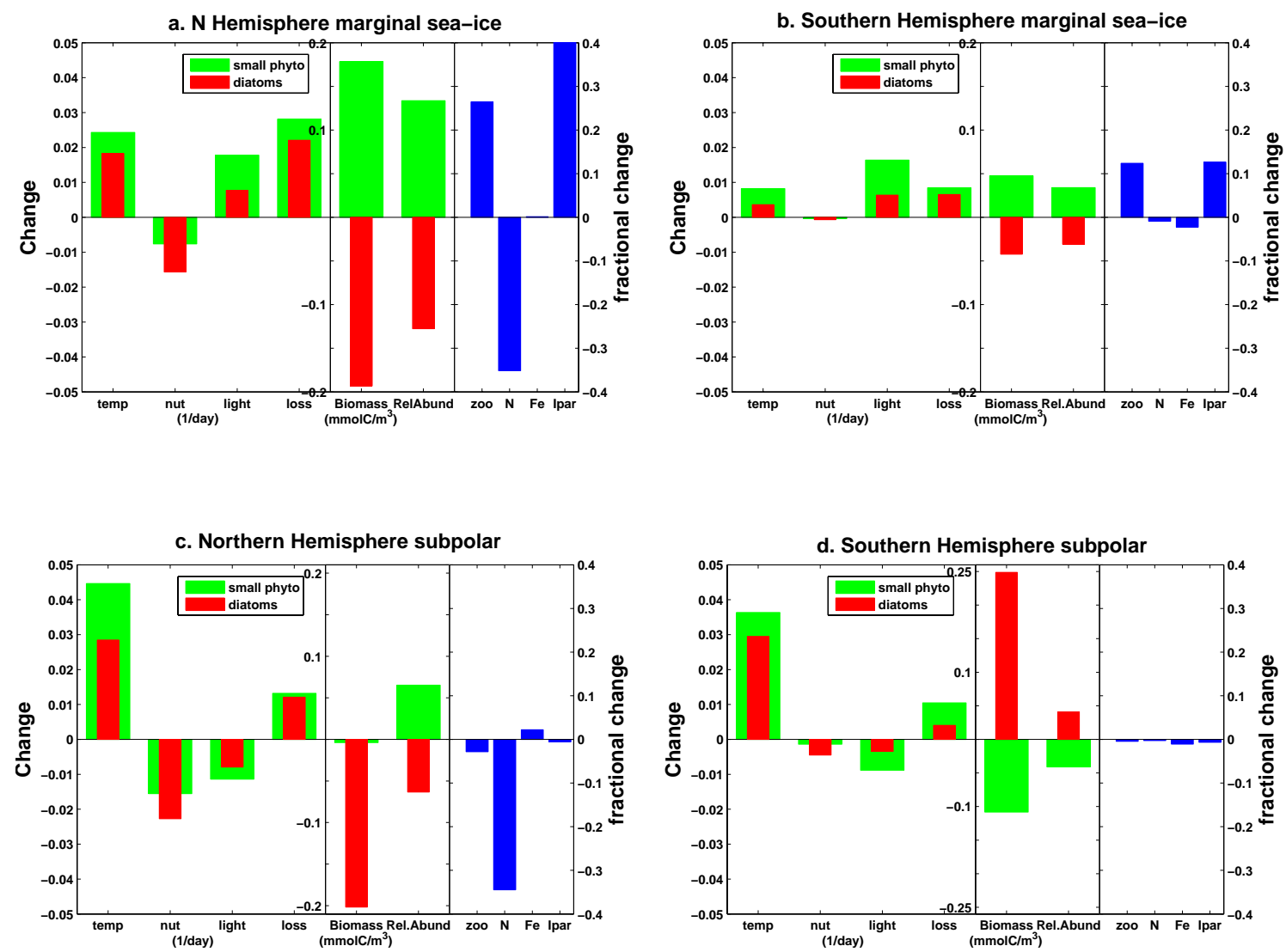

Fig. 8. Same variables as in Fig. 7 averaged for (a) the Northern Hemisphere marginal sea ice biome (b) the Southern Ocean marginal sea ice biome (c) the Northern Hemisphere subpolar biome (d) the Southern Ocean subpolar biome. Light and temperature impacts on growth are most important in the marginal sea ice biomes and subpolar biomes, respectively.

change in nutrient functional response $V_{x}$ is therefore larger for diatoms compared to small phytoplankton, and therefore $\left|\Delta \mu_{\text {diat }}^{\text {nutr }}\right|>\left|\Delta \mu_{\mathrm{sp}}^{\text {nutr }}\right|$ (Figs. 6a-c, 8a-d).

Furthermore, because we are on the right hand side of the critical nutrient value in Fig. 9, nutrient functional response is close to saturation and its slope is small (Fig. 9b, d), i.e., $\left|\Delta V_{x}\right|$ small. We therefore expect that equivalent changes in nutrients result in smaller changes in phytoplankton specific growth rate compared to those observed in the $45^{\circ} \mathrm{S}-45^{\circ} \mathrm{N}$ domain. Since $\left|\Delta V_{x}\right|$ is small, we expect that throughout much of this domain $\left|\Delta \mu_{x}^{\text {nutr }}\right|$ is smaller than $\left|\Delta \mu_{x}^{\text {temp }}\right|$ or $\left|\Delta \mu_{x}^{\text {light }}\right|$. As discussed below and illustrated in Fig. 11e$\mathrm{f}$, temperature dominates the phytoplankton response in the $45^{\circ} \mathrm{S}-60^{\circ} \mathrm{S}$ band, while light becomes critical and governs the small phytoplankton bloom in the Antarctic marginal seaice zone, i.e. $\Delta \mu_{x} \cong \Delta \mu_{x}^{\text {light }}$.

\subsection{The impact of temperature on phytoplankton growth}

Moving from the nutrient effect to the temperature effect, we next analyze the contribution of temperature to the change in growth rate over the 21 st century (1980-2100), $\Delta \mu_{x}^{\text {temp }}$, as defined in Eq. (12c), for various phytoplankton species. Since the temperature sensitivity of growth rate $\left(T_{\mathrm{f}}\right.$ in Eq. 3 ) is the same for all modeled phytoplankton groups, changes in temperature do not lead directly to differential effects on phytoplankton growth $\left(\Delta T_{\mathrm{f}}\right.$ same for all species in Eq. (12c)). Rather, the temperature impact is indirect. Differences in the initial nutrient functional response $V_{x}$ and light limitation function $L_{x}$ contribute to differences in $\Delta \mu_{x}^{\text {temp }}$ between species, as explained below.

Referring back to the light limitation equation (Eq. 6), the product $L_{x} V_{x}$, which enters into Eq. (12c), has the general form $L_{x} V_{x}=\left(1-e^{-\alpha_{x} \theta_{x}^{c} I_{\mathrm{par}} /\left(\mu_{\mathrm{ref}} V_{x} T_{\mathrm{f}}\right)}\right) \cdot V_{x}$. The function $\left(1-e^{-a / V_{x}}\right) \cdot V_{x}$ is monotonic and increasing in $V_{x}$ for a positive $a$. Small phytoplankton have lower half saturation coefficients and larger nutrient functional response than diatoms everywhere in the ocean, i.e., $V_{\mathrm{sp}}>V_{\text {diat }}$, which necessarily implies $\left(1-e^{-a / V_{\mathrm{sp}}}\right) \cdot V_{\mathrm{sp}}>\left(1-e^{-a / V_{\text {diat }}}\right) \cdot V_{\text {diat }}$. Since $\alpha_{\text {diat }}=\alpha_{\mathrm{sp}}$ and the variability in $\theta_{x}^{c}$ is negligible compared to that in $V_{x}$, we can show that:

$$
\begin{aligned}
& \left(1-e^{-\alpha_{\mathrm{sp}} \theta_{\mathrm{sp}}^{c} I_{\mathrm{par}} /\left(\mu_{\mathrm{ref}} V_{\mathrm{sp}} T_{\mathrm{f}}\right)}\right) \cdot V_{\mathrm{sp}} \\
& \quad>\left(1-e^{-\alpha_{\text {diat }} \theta_{\text {diat }}^{c} I_{\mathrm{par}} /\left(\mu_{\text {ref }} V_{\text {diat }} T_{\mathrm{f}}\right)}\right) \cdot V_{\text {diat }} .
\end{aligned}
$$




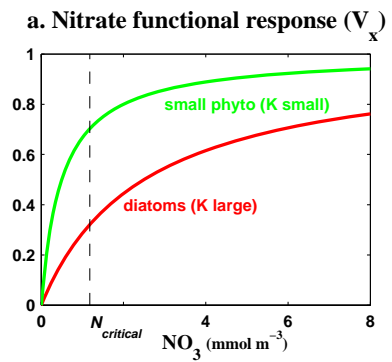

b. Nitrate reponse slope $\left(\partial \mathrm{V}_{\mathrm{x}} / \partial \mathrm{NO}_{3}\right)$
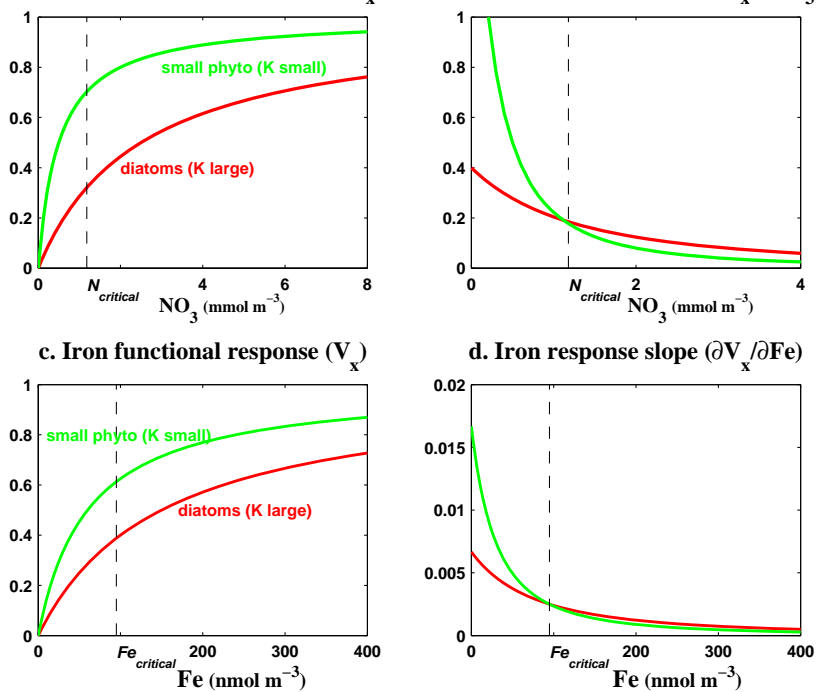

Fig. 9. Illustration of the critical nutrient hypothesis (Sect. 3.2) for nitrate or iron limited regions. For both small phytoplankton (green) and diatoms (red) we show (a) nitrate functional response versus nitrate concentration, (b) the slope of nitrate functional response, (c) iron functional response versus iron concentration and (d) the slope of iron functional response. Below the critical nutrient concentration, a change in ambient nutrient impacts more small phytoplankton than diatoms.

We recognize the terms in the parantheses as the light function terms $L_{\text {sp }}$ and $L_{\text {diat }}$ (Eq. 6) and

$\mu_{\text {ref }} \cdot L_{\mathrm{sp}} V_{\mathrm{sp}}>\mu_{\text {ref }} \cdot L_{\text {diat }} V_{\text {diat }}$

therefore holds everywhere in the ocean. Temperature increases everywhere at the ocean surface with climate change such that $\Delta T_{\mathrm{f}}$ is positive. Therefore, we predict from Eqs. (12c) and (18) that:

$\Delta \mu_{\mathrm{sp}}^{\mathrm{temp}}>\Delta \mu_{\text {diat }}^{\text {temp }}>0$

Increasing temperature acts to increase phytoplankton growth rate and biomass. Figures $6 \mathrm{~d}$, e, f, 7 and 8 confirm our prediction (Eq. 19): a given increase in temperature preferentially increases small phytoplankton compared to diatoms in all ocean regions.

In order to compare the relative roles of the nutrient and temperature contributions to the total phytoplankton growth rate, we ask where $\left|\Delta \mu_{x}^{\text {nutr }}\right|>\left|\Delta \mu_{x}^{\text {temp }}\right|$ holds in the ocean? From $V_{x}=N /\left(N+K_{x}\right)$ and Eq. (3) we derive, assuming small changes in $T$ and $N$ :

$\Delta V_{x}=\frac{K_{x}^{N} \cdot \Delta N}{\left(N+K_{x}^{N}\right)^{2}}$ and $\Delta T_{\mathrm{f}}=\frac{\ln 2}{10\left({ }^{\circ} \mathrm{C}\right)} \cdot T_{\mathrm{f}} \cdot \Delta T$

where $N$ corresponds to some average value of the limiting nutrient (nitrate, iron, silica or phosphate), $T$ is temperature and $K_{x}$ is the half saturation coefficient corresponding to a a. Critical nutrient hypothesis

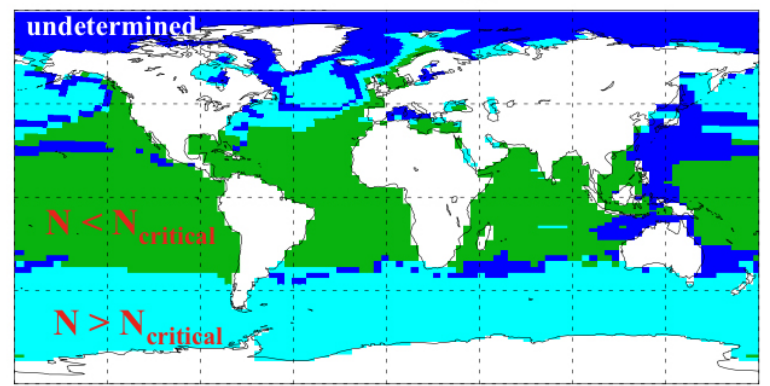

b. Model results: Phytoplankton response to nutrient changes

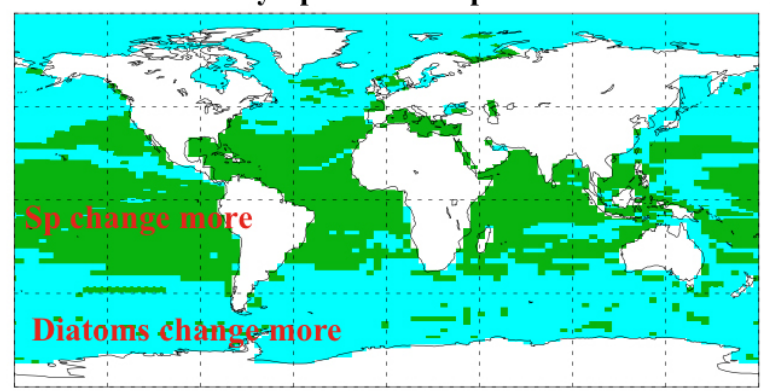

Fig. 10. (a) Critical nutrient hypothesis. Green areas: $N \leq N_{\text {critical }}$ and hypothesis predicts that small phytoplankton specific growth rates should change more with nutrient change than diatom growth rates. Light blue areas: $N>N_{\text {critical }}$ and diatom growth rates should change more than small phytoplankton growth rates. Dark blue areas: no theoretical prediction possible as diatoms and small phytoplankton are limited by different nutrients (e.g., diatoms are Si limited while small phyto are $\mathrm{N}$ limited in $\mathrm{W}$ Pacific). Area separation based on point-by-point comparisons of surface limiting nutrient $\left(\mathrm{NO}_{3}\right.$ or $\mathrm{Fe}$ or $\left.\mathrm{PO}_{4}\right)$ values with the corresponding critical nutrient value calculated from Eq. (17) in the text. (b) Climate model results. Green areas: model regions where small phytoplankton growth rates change more than diatom growth rates in response to nutrient perturbations $\left|\Delta \mu_{\mathrm{sp}}^{\text {nutr }}\right|>\left|\Delta \mu_{\text {diat }}^{\text {nutr }}\right|$. Light blue areas: diatom growth rates change more $\left|\Delta \mu_{\text {diat }}^{\text {nutr }}\right|>\left|\Delta \mu_{\mathrm{sp}}^{\text {nutr }}\right|$. $\Delta \mu_{\mathrm{sp}}^{\text {nutr }}, \Delta \mu_{\text {diat }}^{\text {nutr }}$ terms calculated as linear trends for the 1980-2100 period (as in Figs. 6, 7, 8). The critical nutrient hypothesis predicts well the model results; green and light blue areas in (a) coincide nicely with green and light blue areas in (b), respectively.

specific nutrient $N$ and phytoplankton type $x$. Combining $V_{x}=N /\left(N+K_{x}\right)$, Eqs. 20 and $(12 \mathrm{~b})-(12 \mathrm{c})$ we can show that:

$\left|\Delta \mu_{x}^{\text {nutr }}\right| \geq\left|\Delta \mu_{x}^{\text {temp }}\right|$ if $|\Delta N| \geq \frac{N \cdot\left(N+K_{x}^{N}\right)}{K_{x}^{N}} \cdot \frac{\ln 2}{10\left({ }^{\circ} \mathrm{C}\right)} \cdot|\Delta T|$
$\left|\Delta \mu_{x}^{\text {nutr }}\right|<\left|\Delta \mu_{x}^{\text {temp }}\right|$ if $|\Delta N|<\frac{N \cdot\left(N+K_{x}^{N}\right)}{K_{x}^{N}} \cdot \frac{\ln 2}{10\left({ }^{\circ} \mathrm{C}\right)} \cdot|\Delta T|$

We use the 1980-2100 linear trends in the limiting nutrient and temperature to calculate $\Delta N$ and $\Delta T$ and we predict from the above equation the regions where growth rate change due to nitrate or iron should dominate over the growth rate change due to temperature for each of our phytoplankton types. These theoretically predicted regions (green regions 


\section{Diatoms}

a. Theory

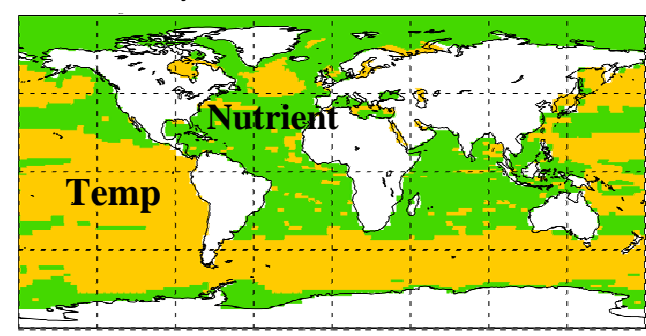

c. Model

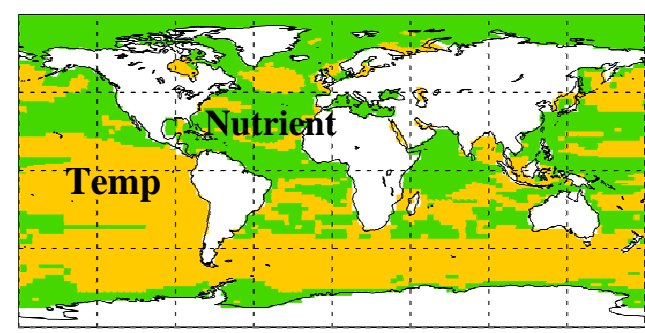

e. Model

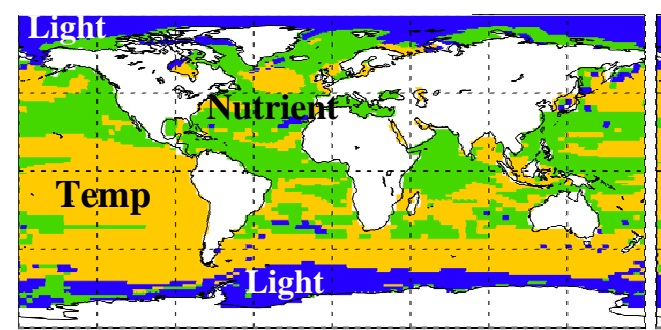

\section{Small phytoplankton}
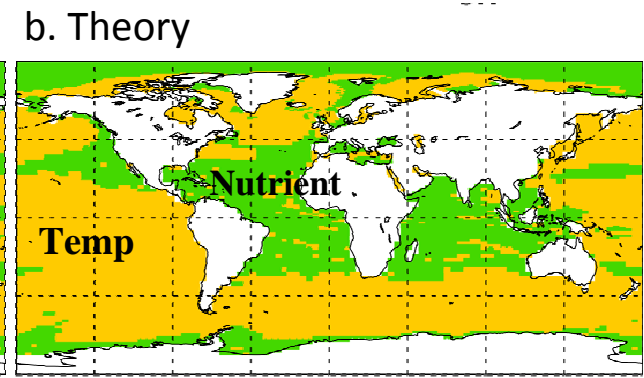

d. Model

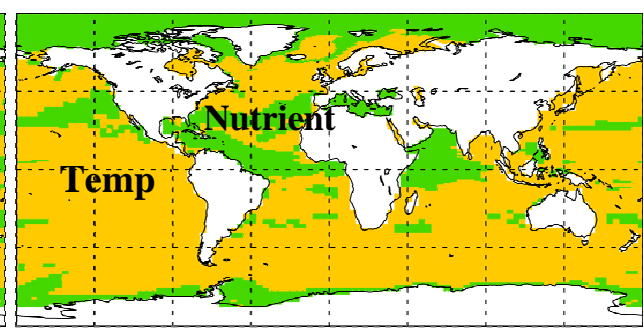

f. Model

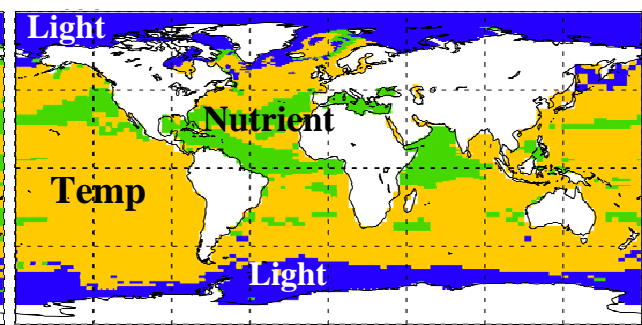

Fig. 11. (a-b): Theoretical prediction based on Eq. (21) of whether the 1980-2100 growth rate change due to nutrient limitation should be larger than the growth rate change due to temperature. Prediction shown for (a) diatoms and (b) small phytoplankton. Green: growth rate change due to nutrient (either nitrate or iron) dominates; Yellow: growth rate change due to temperature dominates. (c-f) Model Results: (c-d): regions where the model calculated 1980-2100 growth rate trend due to nutrient limitation is larger (green) or smaller (yellow) than the growth rate change due to temperature for diatoms (c) and small phytoplankton (d). (e-f) Shows regions where the model calculated 1980-2100 growth rate trend is dominated by either the nutrient (green), temperature (yellow) or by the light (blue) contributions (Eqs. 1112).

in Fig. 11a, b) match remarkably well the results of climate change projections (green regions in Fig. 11c, d). The model projected regions are calculated by comparing the 19802100 changes in $\mu_{\text {diat }}^{\text {nutr }}$ and $\mu_{\text {diat }}^{\text {temp }}$ and the changes in $\mu_{\mathrm{sp}}^{\text {temp }}$ and $\mu_{\mathrm{sp}}^{\text {temp }}$, respectively. It is encouraging that the predictions from the linearized perturbation analysis are consistent with the results from the fully prognostic CCSM simulations. This suggests that other factors that could influence the prognostic simulations (e.g., lateral advection, multi-stressors, grazing) are of second order importance.

Analysis of the inequalities on the RHS of Eq. (21) can help us understand the spatial patterns of dominance of $\Delta \mu^{\text {nutr }}$ versus $\Delta \mu^{\text {temp }}$ in Fig. 11. The nutrient term $\Delta \mu^{\text {nutr }}$ dominates over the temperature term $\Delta \mu^{\text {temp }}$ (i.e., $\Delta N$ wins in the inequalities on the RHS of Eq. (21)) in the Atlantic and
Indian midlatitudes where the nitrate decrease is significant and the background nitrate values are very small due to efficient biology (Fig. 4b, a). The temperature term dominates over the nutrient term in regions where the temperature increase $\Delta T$ is large (e.g., the Pacific midlatitudes) or where the background nutrients are large due to inefficient biology (such as most of the Southern Ocean and the Equatorial Pacific). Finally, since $K_{\mathrm{sp}}$ is smaller than $K_{\text {diat }}$, Eq. (21) suggests correctly that regions where changes in specific growth rate are dominated by temperature (i.e., $\left|\Delta \mu_{x}^{\text {temp }}\right|>\left|\Delta \mu_{x}^{\text {nutr }}\right|$ ) should occupy a larger area of the ocean for small phytoplankton compared to diatoms (Fig. 11c, d). The situation becomes slightly more complex in the high latitudes where light is a strong limiting factor for growth, and climate induced changes in $\Delta \mu_{x}^{\text {light }}$ become larger than either $\Delta \mu_{x}^{\text {temp }}$ 
or $\Delta \mu_{x}^{\text {nutr }}$ for both diatoms and small phytoplankton, as illustrated in Fig. (11e, f). This is the subject of the next section.

Finally, we note that our model is parameterized such that temperature affects the rates of growth and grazing in the same direction, i.e., increasing temperature increases both biomass and grazing rates via $T_{\mathrm{f}}$ (Eqs. 2 and 8). Increases in the temperature growth term is therefore partly compensated in all domains by the increase in grazing term (Fig. 8ad), so a small net increase in biomass occurs with increasing temperature. Because of differential grazing coefficients in Eq. (8), grazing has a larger impact on small phytoplankton biomass than on diatom biomass, compensating some of the small phytoplankton-diatom biomass differences induced by the temperature effect on growth.

\subsection{The impact of light on phytoplankton growth}

Next we turn to analyzing the contribution of light to changes in growth rate, $\Delta \mu_{x}^{\text {light }}$, as defined in Eq. (12a), for small phytoplankton and diatoms. At high light (in low latitudes or in the summer) the exponential approaches zero and $\Delta \mu_{x}^{\text {light }}$ becomes small. At low light the exponential $\exp \left(\frac{-\alpha_{x} \cdot \theta_{x}^{c} \cdot I_{\mathrm{par}}}{\mu_{\mathrm{ref}} V_{x} T_{\mathrm{f}}}\right)$ approaches its high limit $\alpha_{x} \theta_{x}^{c} I_{\mathrm{par}} /\left(\mu_{\mathrm{ref}} T_{\mathrm{f}} V_{x}\right)$, and the resulting $\Delta \mu_{x}^{\text {light }}$ depends on the initial light levels, nutrients and temperature. We note an interesting contrast with the low light limit in $\mu_{x}, \alpha_{x} \theta_{x}^{c} I_{\mathrm{par}}$, which does not depend on nutrients or temperature. Figure $6 \mathrm{~g}$, h, i confirms that the impact of changing light on growth rate is larger in the (low light) high latitudes compared to low latitudes.

The light contribution to the growth rate change $\Delta \mu_{x}^{\text {light }}$ dominates the nutrient or temperature contributions in the Arctic and Antarctic marginal sea-ice biomes (Fig. 8a-b and also Fig. 11e-f). According to Eq. (12a), the sign of the light limitation contribution to the growth rate, $\Delta \mu_{x}^{\text {light }}$, is given by the sign of

$S_{x}=\left(\frac{\Delta I_{\mathrm{par}}}{I_{\mathrm{par}}}-\frac{\Delta V_{x}}{V_{x}}-\frac{\Delta T_{\mathrm{f}}}{T_{\mathrm{f}}}\right)$

and thus depends on the relative fractional increases of light, nutrient functional response and temperature function. An increase in irradiance $I_{\text {par }}$ will naturally act to increase phytoplankton growth rate, while increases in nutrient functional response and temperature will act to decrease the growth rate. A close analysis of Eq. (12a) shows that light enhances the growth of small phytoplankton and diatoms in both the Arctic and the Antarctic ice regions (i.e., $\Delta \mu \mu_{\mathrm{sp}}^{\text {light }}$ and $\Delta \mu_{\text {diat }}^{\text {light }}$ positive, see Fig. 8a, b) primarily because of an increase in $I_{\text {par }}$ from 1980 to 2100 (partly due to dwindling ice cover), combined with a pronounced decrease in limiting nutrients and thus $\Delta V_{x}$ in the Arctic. Additionally, $\mu_{x}^{\text {light }}$ decreases over most of the Pacific because of enhanced warming $\left(\Delta T_{\mathrm{f}}>0\right)$, while it increases locally in the North Pacific and North Atlantic (around $30^{\circ}-45^{\circ} \mathrm{N}$ ), Equatorial Atlantic and North In- dian Ocean largely due to decreased nutrient functional response $\left(\Delta V_{x}<0\right)$.

We next compare the terms $\Delta \mu_{\text {diat }}^{\text {light }}$ and $\Delta \mu_{\mathrm{sp}}^{\text {light }}$. Smaller nitrate and iron half saturation coefficients for small phytoplankton and very similar nutrient limitation patterns (Fig. 1) ensure that $V_{\mathrm{sp}}>V_{\text {diat }}$ everywhere. Since $\alpha_{\mathrm{sp}}=\alpha_{\text {diat }}$ in our model and differences in $\theta_{x}^{c} / V_{x}$ are dominated by differences in $V_{x}$, we can write:

$\exp \left(\frac{-\alpha_{\mathrm{sp}} \cdot \theta_{\mathrm{sp}}^{c} \cdot I_{\mathrm{par}}}{\mu_{\mathrm{ref}} V_{\mathrm{sp}} T_{\mathrm{f}}}\right)>\exp \left(\frac{-\alpha_{\text {diat }} \cdot \theta_{\mathrm{diat}}^{c} \cdot I_{\mathrm{par}}}{\mu_{\text {ref }} V_{\text {diat }} T_{\mathrm{f}}}\right)$.

Assuming that differences in $S_{\text {diat }}$ and $S_{\text {sp }}$ are small relative to the above inequality, we predict that overall changes in the light limitation growth terms (Eq. 12a) are more pronounced for small phytoplankton than for diatoms:

$$
\left|\Delta \mu_{\mathrm{sp}}^{\text {light }}\right|>\left|\Delta \mu_{\text {diat }}^{\text {light }}\right|
$$

Analysis of the light limitation growth terms in Fig. 6g, h, i and Figs. 7-8 confirms the validity of Eq. (22) over most of the ocean. A given change in light will therefore affect more small phytoplankton than diatoms. An implication of Eq. (22) is that in the Arctic and Antarctic marginal sea-ice biomes in which light $I_{\mathrm{par}}$ increases with climate change, $S>0$ and $\Delta \mu_{\mathrm{sp}}^{\text {light }}>\Delta \mu_{\text {diat }}^{\text {light }}>0$. Here, $\Delta \mu_{x}^{\text {light }}$ is large enough to dominate the total growth rate change and small phytoplankton biomass preferentially increases over diatom carbon, as confirmed by Fig. 8a, b. Increasing cloud cover decreases surface irradiance in the subtropics. Light becomes more limiting for small phytoplankton, i.e. $\mu_{\mathrm{sp}}^{\text {light }}$ decreases more than $\mu_{\text {diat }}^{\text {light }}$ (Fig. 6g, h, i). This enhances the observed trend in $\Delta \mu_{x}^{\text {nutr }}$ whereby nutrients become more limiting for small phytoplankton, further reducing small phytoplankton over diatoms (Fig. 7).

Interestingly, the differential impact of light on different species (Eq. 22) is indirectly due to differences in the nutrient functional responses $V_{\mathrm{sp}}$ and $V_{\text {diat }}$, as was the case for temperature (Eq. 19). Finally, we note that inequality Eq. (22) will need to be re-evaluated in future work for the more general case in which there are significant differences in $\alpha_{\mathrm{sp}}$ and $\alpha_{\text {diat }}, \mu_{\text {ref }}^{\mathrm{sp}}$ and $\mu_{\text {ref }}^{\text {diat }}$, respectively.

\subsection{On the relative contribution of small phytoplankton and diatoms to the carbon pool}

We have argued above that climate driven temperature, light, and low-mid latitude nutrient changes affect small phytoplankton biomass more than diatom biomass. It is, however, not straight-forward to extrapolate our arguments to relative abundances. Figures 7 and 8 illustrate the complex relationship between biomass and relative (or fractional) abundance. Assuming that diazotrophs are a negligible contribution to the total carbon pool, the time change in the fractional 
abundance of diatoms can be written, after a couple of basic manipulations, as:

$$
\Delta\left(\frac{P_{\text {diat }}}{P_{\mathrm{sp}}+P_{\text {diat }}}\right)=\ldots=\frac{P_{\text {diat }} P_{\mathrm{sp}}}{\left(P_{\mathrm{sp}}+P_{\text {diat }}\right)^{2}}\left(\frac{\Delta P_{\text {diat }}}{P_{\text {diat }}}-\frac{\Delta P_{\mathrm{sp}}}{P_{\mathrm{sp}}}\right)
$$

The relative (or fractional) abundance of diatoms depends on the difference between the relative diatom biomass change $\left(\Delta P_{\text {diat }} / P_{\text {diat }}\right)$ and the relative small phytoplankton change $\left(\Delta P_{\mathrm{sp}} / P_{\mathrm{sp}}\right)$.

Over most of the $45^{\circ} \mathrm{S}-45^{\circ} \mathrm{N}$ region nutrient decrease (due to climate change) results in a larger absolute decrease in small plankton biomass compared to diatoms: $\left|\Delta P_{\mathrm{sp}}\right|>\left|\Delta P_{\text {diat }}\right|$. However, over most of this region small phytoplankton dominate $P_{\mathrm{sp}} \gg P_{\text {diat }}$, such that the relative biomass decrease is actually smaller for small phytoplankton: $\left|\Delta P_{\mathrm{sp}} / P_{\mathrm{sp}}\right|<\left|\Delta P_{\text {diat }} / P_{\text {diat }}\right|$. and from Eq. (23):

$\operatorname{Sign}\left[\Delta\left(\frac{P_{\text {diat }}}{P_{\text {sp }}+P_{\text {diat }}}\right)\right]=\operatorname{Sign}\left[\frac{\Delta P_{\text {diat }}}{P_{\text {diat }}}\right]$

We therefore expect on average, in the $45^{\circ} \mathrm{S}-45^{\circ} \mathrm{N}$ biome, a decrease in the proportion of diatoms and an increase in the proportion of small phytoplankton to total biomass with climate change in the low and mid-latitude regime (Figs. 3e, 7 ), in agreement with previous modeling and observational studies (Bopp et al., 2005; Cermeno et al., 2009).

In the light limited marginal sea-ice biomes, an increase in light acts to primarily increase $P_{\mathrm{sp}}, \Delta P_{\mathrm{sp}}>\Delta P_{\text {diat }}$. Since $P_{\text {diat }}$ is of the same order of magnitude or larger than $P_{\mathrm{sp}}$, $\Delta P_{\mathrm{sp}} / \Delta P_{\mathrm{sp}}>\Delta P_{\text {diat }} / P_{\text {diat }}$ and therefore from Eq. (23):

$\operatorname{Sign}\left[\Delta\left(\frac{P_{\text {diat }}}{P_{\mathrm{sp}}+P_{\text {diat }}}\right)\right]=\operatorname{Sign}\left[-\frac{\Delta P_{\mathrm{sp}}}{P_{\mathrm{sp}}}\right]$

In conclusion, increases in light and temperature in the marginal sea-ice biomes act to decrease the proportion of diatoms and increase the proportion of small phytoplankton to total biomass (Fig. 8a, b). We note conceptual agreement with Agawin et al. (2000) and Moran et al. (2010), who experimentally noticed shifts in the total community to smaller sizes with an increase in temperature.

\section{Discussion}

Assuming a multiplicative growth equation (Eq. 2), identical temperature dependence of growth for diatoms and small phytoplankton and the Geider et al. (1998) formalism for light limitation, we demonstrated that climate driven increases in temperature and changes in light always preferentially affect small phytoplankton compared to diatoms (Sects. 3.3-3.4). We showed that the differential phytoplankton responses to changes in light and temperature are indirectly driven by interspecies differences in the nutrient functional response terms $\left(V_{x}=N /\left(K_{x}+N\right)\right)$. The increases in temperature and light are most important in the Subpolar
Southern Ocean biome and the marginal sea-ice biomes, respectively, where they lead to increases in small phytoplankton biomass and relative abundance. Below we analyze separately the marginal sea-ice biomes and the subpolar biomes.

In the marginal sea-ice biome, light limitation is important, with diatoms and small phytoplankton blooming in the spring and summer when light allows it. Decreasing ice cover and increased stratification with global warming result in more light availability in spring and summer, and are primarily responsible for the observed ecosystem changes.

In the North Atlantic-Arctic Ice biome, small phytoplankton are iron limited in fall and winter and nitrogen limited in spring and summer, while diatoms are nitrogen limited at all times. More stratification makes nitrate more limiting to both species in spring and summer. Temperature dependent increases in grazing rates compensates largely for temperature dependent increases in phytoplankton growth (increased linear loss and aggregation play a smaller role; Fig. 8a). At the elevated nutrient background levels, small phytoplankton are less sensitive to the decrease in nitrogen than diatoms, as expected from the critical nutrient hypothesis. Small phytoplankton also react better to the increase in light availability, in agreement with Eq. (22). As a consequence, small phytoplankton increase with climate change, while diatom spring and summer blooms decrease primarily due to nutrient decline.

In the marginal sea-ice biome adjacent to Antarctica both small phytoplankton and diatoms are iron and light limited. The observed increase of small phytoplankton is dominated by increases in light availability primarily due to retreating sea ice (Fig. 8b). Increased diatom grazing, loss and aggregation compensate for the increase in light and contribute to an average decrease in diatom biomass and relative abundance. Small phytoplankton increase dominates such that total phytoplankton biomass and total zooplankton biomass both increase in time. In summary, a stronger response to increased light makes small phytoplankton more competitive in the ice biomes relative to diatoms.

In the Subpolar North Atlantic, diatoms are primarily nitrate (and in some locations iron) limited, while small phytoplankton are primarily light limited. Stronger stratification implies a thinner mixed layer depth and a decrease in surface nitrate by $1-2 \mathrm{mmol} / \mathrm{m}^{3}$. In this high nutrient regime nitrate decrease preferentially limits diatoms (in agreement with our hypothesis, Sect. 3.2), such that diatom biomass and relative abundance both decrease (Fig. 8c). Minimal changes in small phytoplankton are due to compensating effects on biomass growth of increased temperature on one hand and increased grazing, decreased nutrients and light on the other. Small zooplankton decrease follows the diatom decrease.

In the Southern Ocean subpolar biome the increase in diatom growth rate and biomass is clearly dominated by the increasing temperature term (Fig. 8d). Both surface and average mixed layer light decrease in this region. The decrease is most pronounced at the surface (a $47 \%$ reduction), because 
of increased cloudiness. In agreement with our theoretical analysis (Eq. 22) decreasing light preferentially limits small phytoplankton, ultimately driving, together with increased grazing on small phytoplankton, a decrease in small phytoplankton biomass. Zooplankton increase slightly in the Subpolar South Atlantic due to the diatom increase and decrease slightly in the Subpolar South Pacific due to the small phytoplankton decrease. Averaged over the Southern Ocean subpolar biome, there is almost no change in zooplankton carbon. In contrast to the marginal ice biome, diatoms become more competitive than small phytoplankton in the Southern Hemisphere subpolar biome because they are less sensitive to decreases in light and they are grazed less than the small phytoplankton (Fig. 8d).

We conclude that climate driven changes in nutrients, temperature and light have regionally varying and sometimes counterbalancing impacts on phytoplankton biomass and structure, with nutrients and temperature dominating in the $45^{\circ} \mathrm{S}-45^{\circ} \mathrm{N}$ band and light-temperature effects dominating in the marginal sea-ice and subpolar regions.

The main contribution of this paper is to propose the existence of a critical nutrient threshold, below (above) which any nutrient changes will affect more (less) small phytoplankton biomass than diatom biomass. This nutrient threshold broadly corresponds to $45^{\circ} \mathrm{S}$ and $45^{\circ} \mathrm{N}$, poleward of which biology is inefficient, vertical mixing and therefore nutrients are high and equatorward of which biology is inefficient, vertical mixing is reduced and therefore nutrients are low. The critical nutrient hypothesis is a most useful predictor of carbon changes in the $45^{\circ} \mathrm{S}-45^{\circ} \mathrm{N}$ band, where intensified climate drives nutrient depletion, which decreases small phytoplankton biomass more strongly than diatom biomass (Fig. 7). In high latitudes, the impact of nutrient decrease on phytoplankton biomass (as expressed through the nutrient contribution to the change in growth rate) is more significant for diatoms than for small phytoplankton, and contributes to diatom decrease in the northern marginal sea-ice and subpolar biomes (Fig. 8).

Our critical nutrient hypothesis applies to the large areas of the ocean where both small phytoplankton and diatoms are limited by the same nutrient and is based on a MichaelisMenten representation for nutrient limitation of photosynthesis. To what extent do our findings apply to other models and to the real ocean? Preliminary analysis suggests that the critical nutrient hypothesis also holds in a completely different ecosystem model (GFDL TOPAZ, Dunne et al., 2010). Generalizations of the present work to a broader class of models will be addressed in follow up work, but a couple of initial observations follow.

One question that needs to be addressed further is the role of grazers for future phytoplankton distribution. In our model temperature affects phytoplankton growth and grazing rates equally. However, stronger temperature dependence for heterotrophic processes (such as zooplankton growth) than for autotrophic processes (phytoplankton growth) has been predicted in the context of the metabolic theory of ecology by Lopez-Urrutia et al. (2006). This effect might result in phytoplankton escaping zooplankton grazing at low temperatures where zooplankton perform poorly, perhaps allowing frequent algal blooms to develop in polar regions (Rose and Caron, 2008; Lopez-Urrutia, 2008). The opposite should be true in low latitudes. Furthermore, this mis-match might contribute to a larger impact of increasing temperature on high latitude phytoplankton biomass compared to our present model predictions, and to a smaller impact of increasing temperature on phytoplankton biomass in low latitudes where zooplankton are more active.

This work shows clearly that the equation forms specified in GCMs for nutrient limitation and photosynthetic nutrient uptake influence significantly the behavior of the system under environmental or climate change scenarios. Several authors argue that phytoplankton nutrient uptake should be modeled using "optimal uptake kinetics" (OU) (Pahlow et al., 2005; Smith and Yamanaka, 2007; Smith et al., 2009) rather than as the Michaelis-Menten (MM) function used in this study. Replacing MM with OU alters the control simulation and the concentrations of non-limiting nutrients. Unlike MM kinetics, the OU theory predicts direct nutrient dependence for the maximum growth $\mu_{\text {ref }}$ and for the apparent half saturation coefficient $K_{x}^{N}$. While the type of analysis presented here can clearly be applied to OU kinetics, the derivative of growth as a function of nutrient (and Eq. 12b) will change. Further work needs to be done to understand how this might change our conclusions.

Recent modeling studies (Bopp et al., 2005), laboratory and field data (Jin et al., 2006; Cermeno et al., 2009) have suggested an increase in the relative abundance of small phytoplankton in low and midlatitudes with enhanced stratification. Our model results agree with this (small phytoplankton relative abundance increases in all biomes except for the Southern Hemisphere subpolar), but our analysis points out that (a) climate change can have opposite implications for absolute and relative contributions of small phytoplankton to the total biomass and (b) changes in the absolute values of biomass are mechanistically more meaningful than relative changes. For example, in the $45^{\circ} \mathrm{S}-45^{\circ} \mathrm{N}$ biome climate change results in both (1) a larger drop in the small phytoplankton biomass than in diatom biomass - as predicted by the mechanistically meaningful critical nutrient hypothesis and (2) a relative increase in small phytoplankton biomass, mathematically simply a consequence of small phytoplankton having much larger background biomass in this area. We suggest that both absolute and relative changes in phytoplankton be recorded and analyzed in future climate change studies.

Our work suggests that a deeper theoretical understanding of the basic ecological equations used in global models might help us predict future ecological and biogeochemical climate-driven shifts and point to critical processes that need targeted observations. Mapping phytoplankton community 
composition and its temporal variability from satellite and in-situ measurements is essential for validating our critical nutrient hypothesis and model results and generally for forecasting the evolution of ocean ecology and carbon cycle. A number of investigators have developed algorithms to estimate phytoplankton functional types (e.g., Uitz et al., 2006, 2010; Alvain et al., 2008) and size structure (e.g. Kostadinov et al., 2009, 2010; Mouw and Yoder, 2010) from satellite data. We suggest that satellite estimates of interannual variability in size structure can provide a potential test for our proposed "critical nutrient hypothesis". One idea would be to compare the variability in small and large phytoplankton at locations where plankton variability is primarily due to nutrient changes, both in areas where nutrients are lower and where nutrients are higher than critical values.

\section{Appendix A}

We are interested in how the growth rate of a given phytoplankton species $\mu_{x}=\mu_{\text {ref }} \cdot T_{\mathrm{f}} \cdot V_{x} \cdot L_{x}$ changes with climate change. A first order Taylor approximation to the specific growth rate yields:

$$
\begin{gathered}
\Delta \mu_{x}=\left.\frac{\partial \mu_{x}}{\partial I_{\mathrm{par}}}\right|_{V_{x}, T_{\mathrm{f}} \text { constant }} \cdot \Delta I_{\mathrm{par}}+\left.\frac{\partial \mu_{x}}{\partial V_{x}}\right|_{I_{\mathrm{par}}, T_{\mathrm{f}} \text { constant }} \\
\cdot \Delta V_{x}+\left.\frac{\partial \mu_{x}}{\partial T_{\mathrm{f}}}\right|_{I_{\mathrm{par}}, V_{x} \text { constant }} \cdot \Delta T_{\mathrm{f}}
\end{gathered}
$$

Taking into account the fact that the light limitation function $L_{x}$ is a function of $I_{\mathrm{par}}, V_{x}$ and $T_{\mathrm{f}}$, and using the shorthand $d_{x}=\left(\alpha_{x} \cdot \theta_{x}^{c}\right) / \mu_{\text {ref }}$ the expansion of each of the above three terms gives:

$$
\begin{aligned}
\Delta \mu_{x} / \mu_{\mathrm{ref}}=d_{x} \cdot \exp \left(\frac{-d_{x} \cdot I_{\mathrm{par}}}{V_{x} T_{\mathrm{f}}}\right) \cdot \Delta I_{\mathrm{par}} \\
+\left[T_{\mathrm{f}} L_{x}-V_{x} T_{f} \cdot \frac{d_{x} \cdot I_{\mathrm{par}}}{T_{\mathrm{f}} V_{x}^{2}} \exp \left(\frac{-d_{x} \cdot I_{\mathrm{par}}}{V_{x} \cdot T_{\mathrm{f}}}\right)\right] \cdot \Delta V_{x} \\
+\left[L_{x} V_{x}-V_{x} T_{\mathrm{f}} \cdot \frac{d_{x} \cdot I_{\mathrm{par}}}{V_{x} \cdot T_{\mathrm{f}}^{2}} \exp \left(\frac{-d_{x} \cdot I_{\mathrm{par}}}{V_{x} \cdot T_{\mathrm{f}}}\right)\right] \cdot \Delta T_{\mathrm{f}}
\end{aligned}
$$

where now $I_{\mathrm{par}}, V_{x}$ and $T_{\mathrm{f}}$ are some mean value and deltas are small deviations from this mean. As is customary, we retain only the first order terms in the Taylor expansion, dropping quadratic and higher order terms which tend to be smaller. We rearrange the above equation as follows:

$$
\begin{aligned}
& \Delta \mu_{x} / \mu_{\mathrm{ref}}=\left[d_{x} \cdot \exp \left(\frac{-d_{x} \cdot I_{\mathrm{par}}}{V_{x} T_{\mathrm{f}}}\right) \cdot \Delta I_{\mathrm{par}}-V_{x} T_{\mathrm{f}} \cdot \frac{d_{x} \cdot I_{\mathrm{par}}}{T_{\mathrm{f}} V_{x}^{2}}\right. \\
& \cdot \exp \left(\frac{-d_{x} \cdot I_{\mathrm{par}}}{V_{x} T_{\mathrm{f}}}\right) \cdot \Delta V_{x}-V_{x} T_{\mathrm{f}} \cdot \frac{d_{x} \cdot I_{\mathrm{par}}}{V_{x} \cdot T_{\mathrm{f}}^{2}} \\
& \left.\cdot \exp \left(\frac{-d_{x} \cdot I_{\mathrm{par}}}{V_{x} T_{\mathrm{f}}}\right) \cdot \Delta T_{\mathrm{f}}\right]+T_{\mathrm{f}} L_{x} \cdot \Delta V_{x}+L_{x} V_{x} \cdot \Delta T_{\mathrm{f}}
\end{aligned}
$$

or after further manipulation:

$$
\begin{array}{r}
\Delta \mu_{x} / \mu_{\mathrm{ref}}=\left[d_{x} \cdot I_{\mathrm{par}} \cdot\left(\frac{\Delta I_{\mathrm{par}}}{I_{\mathrm{par}}}-\frac{\Delta V_{x}}{V_{x}}-\frac{\Delta T_{\mathrm{f}}}{T_{\mathrm{f}}}\right)\right. \\
\left.\cdot \exp \left(\frac{-d_{x} \cdot I_{\mathrm{par}}}{V_{x} T_{\mathrm{f}}}\right)\right]+T_{\mathrm{f}} L_{x} \cdot \Delta V_{x}+L_{x} V_{x} \cdot \Delta T_{\mathrm{f}}
\end{array}
$$

The three terms on the right hand side represent the light function, nutrient and temperature contributions to the growth rate change, respectively, i.e.

$\Delta \mu_{x}=\Delta \mu_{x}^{\text {light }}+\Delta \mu_{x}^{\text {nutr }}+\Delta \mu_{x}^{\text {temp }}$

Acknowledgements. While at WHOI, I. Marinov was supported by National Science Foundation (NSF) Grant ATM06-28582. I. Lima and S. Doney were supported by the Center for Microbial Oceanography, Research, and Education (CMORE) an NSF Science and Technology Center (EF-0424599). We want to thank an anonymous reviewer, who provided many useful comments.

Edited by: L. Bopp

\section{References}

Agawin, N. S. R., Duarte, C. M., and Agustí, S.: Nutrient and temperature control of the contribution of picoplankton to phytoplankton biomass and production, Limnol. Oceanogr., 45, 591600, 2000.

Alvain, S., Moulin, C., Dandonneau, Y., and Loisel, H.: Seasonal distribution and succession of dominant phytoplankton groups in the global ocean: A satellite view, Global Biogeochem. Cy., 22(3), GB3001, doi:10.1029/2007GB003154, 2008.

Armstrong, R. A., Lee, C., Hedges, J. I., Honjo, S., and Wakeham, S. G.: A new, mechanistic model for organic carbon fluxes in the ocean based on the quantitative association of POC with ballast minerals, Deep-Sea Res. Pt. II, 49, 219-236, 2002.

Aumont, O., Maier-Reimer, E., Blain, S., and Monfray, P.: An ecosystem model of the global ocean including $\mathrm{Fe}, \mathrm{Si}$, P colimitations, Global Biogeochem. Cy., 17(2), GB1060, doi:10.1029/2001GB001745, 2003.

Bopp, L., Monfray, P., Aumont, O., Dufresne, J. L., Le Treut, H., Madec, G., Terray, L., and Orr, J. C.: Potential impact of climate change on marine export production, Global Biogeochem. Cy., 15, 81-99, 2001.

Bopp, L., Aumont, O., Cadule, P., Alvain, S., and Gehlen, M.: Response of diatoms distribution to global warming and potential implications: A global modeling study, Geophys. Res. Lett., 32(19), L19606, doi:10.1029/2005GL023653, 2005.

Boyd, P. W. and Doney, S. C.: Modelling regional responses by marine pelagic ecosystems to global climate change, Geophys. Res. Lett., 29(16), 1806, doi:10.1029/2001GL014130, 2002.

Cermeno, P., Dutkiewicz, S., Harris, R. P., Follows, M., Schofield, O., and Falkowski, P. G.: The role of nutricline depth in regulating the ocean carbon cycle, PNAS, 105, 20344, doi:10.1073/pnas.0811302106, 2008.

Collins, W. D., Bitz, C. M., Blackmon, M. L., Bonan, G. B., Bretherton, C. S., Carton, J. A., Chang, P., Doney, S. C., Hack, J. J., Henderson, T. B., Kiehl, J. T., Large, W. G., McKenna, D. S., 
Santer, B. D., and Smith, R. D.: The Community Climate System Model Version 3 (CCSM3), J. Climate, 19(11), 2122-2143, 2006a.

Collins, W. D., Rasch, P. J., Boville, B. A., Hack, J. J., McCaa, J. R., Williamson, D. L., Briegleb, B. P., Bitz, C. M., Lin, S. J., and Zhang, M. H.: The Formulation and Atmospheric simulation of the Community Atmosphere Model Version 3 (CAM3), J. Climate, 19(11), 2144-2161, 2006b.

Doney, S. C.: Plankton in a warmer world, Nature, 444, 695-696, 2006.

Doney, S. C., Lindsay, K., Fung, I., and John, J.: Natural variability in a stable, 1000-yr global coupled climate-carbon cycle simulation, J. Climate, 19(13), 3033-3054, 2006.

Doney, S. C., Lima, I., Moore, J. K., Lindsay, K., Behrenfeld, M. J., Westberry, T. K., Mahowald, N., Glover, D. M., and Takahashi, T.: Skill metrics for confronting global upper ocean ecosystembiogeochemistry models against field and remote sensing data, J. Marine Syst., 76, 95-112, doi:10.1016/j.jmarsys.2008.05.015, 2009.

Falkowski, P. G., Barber, R. T., and Smetacek, V.: Biogeochemical controls and feedbacks on ocean primary production, Science, 281, 5374, 200-206, 1998.

Falkowski, P. G., Katz, M. E., Knoll, A. H., Quigg, A., Raven, J. A., Schofield, O., and Taylor, F. J. R.: The evolution of modern eukaryotic phytoplankton, Science, 305, 354-360, 2004.

Field, C. B., Behrenfeld, M. J., Randerson, J. T., and Falkowski, P.: Primary production of the biosphere: Integrating terrestrial and oceanic components, Science, 281(537), 237-240, 1998.

Follows, M. J., Dutkiewicz, S., Grant, S., and Chisholm, S. W.: Emergent biogeography of microbial communities in a model ocean, Science, 315, 1843-1846, 2007.

Geider, R. J., MacIntyre, H. L., and Kana, T. M.: A dynamic regulatory model of phytoplankton acclimation to light, nutrients, and temperature, Limnol. Oceanogr., 43, 679-694, 1998.

Gent, P. R. and McWilliams, J. C.: Isopycnal Mixing in Ocean Circulation Models, J. Phys. Oceanogr., 20(1), 150-155, 1990.

Jin, X., Gruber, N., Dunne, J. P., Sarmiento, J. L., and Armstrong, R. A.: Diagnosing the contribution of phytoplankton functional groups to the production and export of particulate organic carbon, $\mathrm{CaCO}_{3}$, and opal from global nutrient and alkalinity distributions, Global Biogeochem. Cy., 20, GB2015, doi:10.1029/2005GB002532, 2006.

Kostadinov, T. S., Siegel, D. A., and Maritorena, S.: Retrieval of the particle size distribution from satellite ocean color observations, J. Geophys. Res., 114, C09015, doi:10.1029/2009JC005303, 2009.

Kostadinov, T. S., Siegel, D. A., and Maritorena, S.: Global variability of phytoplankton functional types from space: assessment via the particle size distribution, Biogeosciences, 7, 3239-3257, doi:10.5194/bg-7-3239-2010, 2010.

Large, W. G., McWilliams, J. C., and Doney, S. C.: Oceanic vertical mixing: A review and a model with a nonlocal boundary layer parameterization, Rev. Geophys., 32(4), 363-403, 1994.

Le Quere, C., Aumont, O., Monfray, P., and Orr, J.: Propagation of climatic events on ocean stratification, marine biology, and $\mathrm{CO}_{2}$ : Case studies over the 1979-1999 period, J. Geophys. Res., 108(C12), 3375, doi:10:1029/2001JC000920, 2003.

Le Quere, C., Harrisson, S. P., Prentice, I. C., Buitenhuis, E. T., Aumont, O., Bopp, L., Claustre, H., Da Cunha, L. C., Geider, R.,
Giraud, X., Klaas, C., Kohfeld, K. E., Legendre, L., Manizza, M., Platt, T., Rivkin, R. B., Sathyendranath, S., Uitz, J., Watson, A. J., and Wolf-Gladrow, D.: Ecosystem dynamics based on plankton functional types for global ocean biogeochemistry models, Glob. Change Biol., 11, 2016-2040, 2005.

Lima, I. D. and Doney, S. C.: A three-dimensional, multinutrient, and size-structured ecosystem model for the North Atlantic, Global Biogeochem. Cy., 18(3), GB3019, doi:1029/2003GB002146, 2004.

López-Urrutia, A.: The metabolic theory of ecology and algal bloom formation, Limnol. Oceanogr., 53(5), 2046-2047, 2008.

López-Urrutia, A., San Martin, E., Harris, R. P., and Irigoien, X.: Scaling the Metabolic Balance of the Oceans, PNAS, 103(23), 8739-8744, 2006.

Moore, J. K. and Braucher, O.: Sedimentary and mineral dust sources of dissolved iron to the world ocean, Biogeosciences, 5, 631-656, doi:10.5194/bg-5-631-2008, 2008.

Moore, J. K., Doney, S. C., Kleypas, J. C., Glover, D. M., and Fung, I. Y.: An intermediate complexity marine ecosystem model for the global domain, Deep-Sea Res. Pt. II, 49, 403-462, 2002.

Moore, J. K., Doney, S. C., and Lindsay, K.: Upper ocean ecosystem dynamics and iron cycling in a global threedimensional model, Global Biogeochem. Cy., 18, GB4028, doi:10.1029/2004GB002220, 2004.

Moore, J. K., Doney, S. C., Lindsay, K., Mahowald, N., and Michaels, A. F.: Nitrogen fixation amplifies the ocean biogeochemical response to decadal timescale variations in mineral dust deposition, Tellus B, 58(5), 560-572, 2006.

Moran, X. A. G., López-Urrutia, A., Calvo-Diaz, A., and Li, W. K. W.: Increasing importance of small phytoplankton in a warmer ocean, Glob. Change Biol., 16(3), 1137-1144, 2010.

Mouw, C. B. and Yoder, J. A.: Optical determination of phytoplankton size distribution from global SeaWiFS imagery, J. Geophys. Res., in press, 2010.

Najjar, R. G., Jin, X., Louanchi, F., Aumont, O., Caldeira, K., Doney, S. C., Dutay, J.-C., Follows, M., Gruber, N., Joos, F., Lindsay, K., Maier-Reimer, E., Matear, R. J., Matsumoto, K., Monfray, P., Mouchet, A., Orr, J. C., Plattner, G.-K., Sarmiento, J. L., Schlitzer, R., Slater, R. D., Weirig, M.-F., Yamanaka, Y., and Yool, A.: Impact of circulation on export production, dissolved organic matter and dissolved oxygen in the ocean: results from OCMIP-2, Global Biogeochem. Cy., 21(3), GB3007, doi:10.1029/2006GB002857, 2007.

Pahlow, M.: Linking chlorophyll-nutrient dynamics to the Redfield $\mathrm{N}: \mathrm{C}$ ratio with a model of optimal phytoplankton growth, Mar. Ecol.-Prog. Ser., 287, 33-43, 2005.

Rose, J. M. and Caron, D. A.: Does low temperature constrain the growth rates of heterotrophic protists? Evidence and implications for algal blooms in cold water, Limnol. Oceanogr., 52, 886895, 2007.

Sarmiento, J. L., Slater, R., Barber, R., Bopp, L., Doney, S. C., Hirst, A. C., Kleypas, J., Matear, R., Mikolajewicz, U., Monfray, P., Soldatov, V., Spall, S. A., and Stouffer, R.: Response of ocean ecosystems to climate warming, Global Biogeochem. Cy., 18(3), GB3003, doi:10.1029/2003GB002134, 2004.

Schmittner, A., Oschlies, A., Giraud, X., Eby, M., and Simmons, H. L.: A global model of the marine ecosystem for long-term simulations: Sensitivity to ocean mixing, buoyancy forcing, particle sinking, and dissolved organic matter cycling, Global 
Biogeochem. Cy., 19, GB3004, doi:10.029/2004GB002283, 2005.

Smetacek, V.: Diatoms and the ocean carbon cycle, Protist, 150, 25-32, 1999.

Smith, R. D. and Gent, P. R.: Reference manual for the Parallel ocean Program (POP), ocean component of the Community Climate System Model (CCSM2.0 and 3.0), Tech. Rep. LA-UR02-2484, Los Alamos National Laboratory, available at: http: //www.ccsm.ucar.edu/models/ccsm3.0/pop, 2002.

Smith, S. L. and Yamanaka, Y.: Optimization-based model of multinutrient uptake kinetics, Limnol. Oceanogr., 52, 1545-1558, 2007.

Smith, S. L., Yamanaka, Y., Pahlow, M., and Oschlies, A.: Optimal uptake kinetics: Physiological acclimation explains the pattern of nitrate uptake by phytoplankton in the ocean, Mar. Ecol.-Prog. Ser., 384, 1-12, 2009.

Steinacher, M., Joos, F., Frölicher, T. L., Bopp, L., Cadule, P., Cocco, V., Doney, S. C., Gehlen, M., Lindsay, K., Moore, J. K., Schneider, B., and Segschneider, J.: Projected 21st century decrease in marine productivity: a multi-model analysis, Biogeosciences, 7, 979-1005, doi:10.5194/bg-7-979-2010, 2010.
Thornton, P. E., Doney, S. C., Lindsay, K., Moore, J. K., Mahowald, N., Randerson, J. T., Fung, I., Lamarque, J.-F., Feddema, J. J., and Lee, Y.-H.: Carbon-nitrogen interactions regulate climate-carbon cycle feedbacks: results from an atmosphereocean general circulation model, Biogeosciences, 6, 2099-2120, doi:10.5194/bg-6-2099-2009, 2009.

Tilman, D.: Resource competition between planktonic algae: an experimental and theoretical approach, Ecology, 58, 338-348, 1977.

Uitz, J., Claustre, H., Morel, A., and Hooker, S. B.: Vertical distribution of phytoplankton communities in open ocean: An assessment based on surface chlorophyll, J. Geophys. Res., 111, C08005, doi:10.1029/2005JC003207, 2006.

Uitz, J., Claustre, H., Gentili, B., and Stramski, D.: Phytoplankton class-specific primary production in the world's oceans: Seasonal and interannual variability from satellite observations, Global Biogeochem. Cy., 24, GB3016, doi:10.1029/2009GB003680, 2010.

Yeager, S. G., Shields, C. A., Large, W. G., and Hack, J. J.: The low-resolution CCSM3, J. Climate, 19, 2545-2566, 2006. 